\title{
Sources of TFP Growth: Occupational Choice and Financial Deepening
}

\author{
Hyeok Jeong ${ }^{\ddagger}$ and Robert M. Townsend ${ }^{\S *}$
}

November $2006^{\dagger}$

\begin{abstract}
This paper explains and measures the sources of TFP by developing a method of growth accounting based on an integrated use of transitional growth models and micro data. We decompose TFP growth into the occupational-shift effect, financial-deepening effect, capital-heterogeneity effect, and sectoral-Solowresiduals. Applying this method to Thailand, which experienced rapid growth with enormous structural changes between 1976 and 1996, we find that 73 percent of TFP growth is explained by occupational shifts and financial deepening, without presuming exogenous technical progress. Expansion of credit is a major part. We also show the role of endogenous interaction between factor price dynamics and the wealth distribution for TFP.
\end{abstract}

JEL Classification: O47, O16, J24, D24.

Keywords: Total Factor Productivity, Occupation Choice, Financial Deepening

\section{Introduction}

This paper explains and measures the sources of total factor productivity (TFP) growth by developing a method of growth accounting based on an integrated use of transitional growth models and micro data. TFP growth is measured as residual, total output growth less the weighted sum of input growth, the "Solow residual." By definition, this residual growth measures the improvement of productivity in a Hicks-neutral aggregate production function. However, the improvement of aggregate efficiency measured in this way can come from various sources, which typically remain unknown inside the residual. As Abramovitz (1956) puts it, the Solow residual represents a "measure of our ignorance" of the growth process. Jorgenson and Griliches (1967) suggest that careful measurement and correct model specification can weed out "errors." Their accompanying empirical work showed that careful measurement of education and capital utilization does curtail the size of the residual, but it remained the major part. ${ }^{1}$ Most of the subsequent empirical work focuses on careful measurement, either

${ }^{*} \ddagger$ Department of Economics, University of Southern California; §Department of Economics, University of Chicago. We thank Richard Rogerson for his clarifying and helpful discussion. The comments from the participants of the Minnesota Workshop in Macroeconomic Theory 2004, Stanford Institute for Theoretical Economics (SITE) Summer Workshop 2004, European Meeting and North American Summer Meeting of the Econometric Society 2004, NEUDC 2004, Iowa Conference of Economic Development, and seminars at USC Marshall School, Penn State University, UCLA, and UCSD are also appreciated. Financial support from NSF (SES-0318340) and NICHD (R01 HD27638) is gratefully acknowledged. Corresponding E-mails: hjeong@usc.edu; rtownsen@midway.uchicago.edu.

${ }^{\dagger}$ The first drafts of the paper were circulated around December 2003 under the title of "A Cautionary Tale of Total Factor Productivity Analysis: Decomposition of the Residual."

${ }^{1}$ The portion of the residual for the U.S. growth during the 1950-1962 period was reduced to $54 \%$, a much smaller number than the original estimates, $86 \%$ by Abramovitz (1956), or $88 \%$ by Solow (1957). In fact, Jorgenson and Griliches (1967) reduced the portion to $5 \%$ in their original paper, but corrected this to $54 \%$ upon the criticism of Denison (1969) of their excessively wide adjustment in capital utilization, e.g., by including residential housing. 
by broadening the concept of capital, e.g., including human capital, or by distinguishing sectors, but it continues to confirm that the size of the residual is large.

At the cross-country level, Klenow and Rodríguez-Clare (1997) and Prescott (1998) argue that it is TFP rather than capital that determines the levels and changes in international income differences, even if the concept of capital is broadened to include intangible capital, human capital and organization capital. ${ }^{2}$ Caselli (2005) provides an updated survey of this "development accounting." From a series of depression studies using the growth accounting framework, Kehoe and Prescott (2002) find that changes in TFP are also crucial in accounting for within-country business fluctuation. ${ }^{3}$ They suggest various types of possible policies behind the changes in TFP and call for micro studies for future research, saying "absent careful micro studies at firm and industry levels, we can only conjecture as to what these (good and bad) policies are." Likewise the fundamental idea of Jorgenson and Griliches (1967) is that productivity growth should be explained, not simply measured, and both theory and measurement are crucial in doing so. This paper attempts to fill this gap by identifying the underlying sources of the residual growth via an integrated use of models and micro data.

"Technical change" in the aggregate production function, as Solow (1957) emphasized, can be any kind of shift in the production function at the aggregate level. When an economy is engaged in structural transformation, compositional changes among sectors or activities, across which productivity levels differ on the extensive margin, contribute not only to output growth but also to productivity growth, without true underlying technical change. Here, we use a growth model that makes explicit its micro underpinnings, namely occupational choice and limited access to credit, and features transitions. ${ }^{4}$ The model has two different kinds of technology, traditional and modern. This has deep roots in the development literature, for example the well-known contributions of Lewis (1954) and Ranis and Fei (1961). The modern technology uses hired labor and capital and has fixed setup costs, while the traditional technology, as a simplification, provides constant subsistence income using self-employed labor alone. Occupational choices into the accompanied technology are based on presumed differentials in entrepreneurial talent in the population. However, for agents who do not have access to credit, occupational choices are subject to an additional constraint, individual wealth, as in Lloyd-Ellis and Bernhardt (2000) and Banerjee and Newman (1993). In sum, technological blueprints are available to everyone, but only a subset of agents adopt the modern technology due to heterogeneity in wealth and talent, and limited access to credit generates a mismatch between talent and wealth in occupational choice. Productivity thus depends on efficiency

\footnotetext{
${ }^{2}$ Klenow and Rodríguez-Clare (1997) suggest that TFP accounts for at least 60 percent of the level difference and 85 to 91 percent of growth rate differences across countries. The portion of TFP for level difference reaches 89 percent in Prescott (1998).

${ }^{3}$ The nine coutries included in their study are Canada, France, Germany, Italy, and the U.K. in the interwar period, and Argentina, Chile, and Mexico in the 1980's, and Japan in the 1990's.

${ }^{4}$ The empirical importance of structural change on economic growth was documented early by Kuznets (1966). The theoretical importance of transition in understanding the dynamics of growth and development was emphasized early by Hicks (1965) and Schultz (1990), and recently reaffirmed by Lucas (2004). Hansen and Prescott (2002), and Gollin, Parente, and Rogerson (2002) illustrate that incorporating structural transformation helps to explain the long term growth path and evolution of the international differences in per capita income.
} 
in allocating talent and capital, which improves as wealth grows and the financial sector expands. Dynamics of the aggregates in the model are also determined by the interaction between the endogenous movements of factor prices and the distribution of wealth. Related, Caselli and Gennaioli (2005) study the effects of imperfect credit markets on TFP using numerical simulation. They focus on dynastic management of family-owned firms, which can be a source of the mismatch between talent and wealth.

We intentionally shut down all sources of exogenous technological change, the presumed typical engine of productivity growth in the existing TFP literature. Thus, for us, productivity growth cannot come from technical change but only from improving allocation efficiency, which in turn depends on distribution of wealth and the efficiency of the financial system. We do this not because we think technical change is unimportant, but rather because we would like to see how well the alternative hypothesis of growth based on occupational choice and financial deepening can explain actual growth of output and TFP.

The relationship between financial development and economic growth was postulated early by Schumpeter (1911), and its empirical patterns were addressed early also by Goldsmith (1969) and McKinnon (1973). Theoretical underpinnings of the relationship have been developed by Townsend (1978, 1983), Greenwood and Jovanovic (1990), and Bencivenga and Smith (1991). Empirical evidence of the finance-growth nexus has been provided by King and Levine (1993) and Levine and Zervos (1998) using cross-country data, by Rajan and Zingales (1998) using industry-level data across countries, and by Beck, Demirgüç-Kunt, and Maksimovic (2002) using firm-level data across countries. In particular, Beck, Levine, and Loayza (2000) find that the positive effect of financial intermediation on GDP growth is through its impact on TFP growth, rather than through the channel of physical capital accumulation and private savings rates.

Most of these contributions are either theoretical or empirical, not tightly linking both. Bergoeing, Kehoe, Kehoe, and Soto (2002) is an important exception that pursues a tight link. They also point to the importance of financial reforms for TFP from the contrasting experience between Mexico and Chile. Erosa and Cabrillana (2005), and Amaral and Quintin (2005) provide steady-state analysis of the effects of financial intermediation for TFP differences across countries. We study the relationship between financial deepening and TFP growth over time within a given country in transition. Our integrated use of a model with micro-macro data for a given country provides direct evidence of the finance-growth nexus in relation to TFP.

There is much supporting evidence of credit constraints and the misallocation of capital in the development literature. Banerjee and Duflo (2005) provide an excellent summary. In the end, they argue that "the lessons from this series of convincing micro-empirical studies in development economics will be lost to growth if they are not brought together in an aggregate context." We explicitly bring a growth model that incorporates credit constraints to an aggregate context and evaluate its quantitative importance on aggregate growth dynamics.

Explicit consideration of occupational choice with credit constraint allows us to decompose TFP growth 
into four components: financial-deepening, occupational-shifts, capital-heterogeneity, and within-sector Solow residuals. Financial deepening relaxes not only the borrowing constraint on factor demands of existing entrepreneurs on the intensive margin, but also constraints on occupational choice on the extensive margin, improving efficiency of matching talent to capital. The magnitude of this effect depends on the gap in profitability between the intermediated firms and non-intermediated firms. Own wealth accumulation also weakens the constraints on the occupational choice and improves the allocation efficiency among agents without access to credit. With differential access to intermediation, the opportunity cost of capital is different across agents in the population. This creates a kind of heterogeneity in capital, and its compositional changes influence measured TFP dynamics. Within-sector Solow residuals contribute a remainder of TFP growth. The magnitude is determined by the movements of factor prices and profits, which interactively evolve with the distribution of wealth and the extent of financial intermediation.

We find our approach successful, as applied to Thailand. Without presuming exogenous technical progress, financial deepening and occupational shifts explain 73 percent of aggregate TFP growth in Thailand for the two decades between 1976 and 1996, when rapid economic growth was accompanied by enormous structural change. Differential profitability and occupational choice can play a key role in understanding TFP for an economy with an imperfect capital market. We show the importance of the wealth distribution for TFP dynamics and entrepreneurship. The relationship between financial deepening and entrepreneurship and the effect of factor price movement on TFP all depend on the wealth distribution. We also show that varying degrees of limited access to credit across sub-groups can be a source of differences in sub-group TFP at a disaggregated level. Finally, take-off wage dynamics, a typical feature of dual economy models, can be generated as an equilibrium phenomenon.

The paper is organized as follows. Section II describes the data. Section III describes the model of individual choices under constraints, and Section IV discusses the implied aggregate dynamics. In Section V, the model is calibrated to the aggregate data, and is simulated using the initial wealth distribution and financial deepening measures observed in the micro data. Section VI develops a method of decomposition of TFP growth and applies the method to both the simulated and the actual Thai economies. Section VII discusses model evaluation as well as sensitivity analysis for parameter selection. Section VIII concludes.

\section{Data}

Thailand experienced fast economic growth as well as enormous structural change between 1976 and 1996. The two most noticeable structural changes were occupational transformation and financial deepening, the key ingredients of the model that we will study. We also observe interesting non-linear patterns of output growth 
with these structural changes. Finally, Thailand provides us with a rich set of both macro and micro data, the combination of which is crucial in the following simulation and decomposition analysis of the TFP growth.

\section{A Standard Growth Accounting}

Figure 1 displays the annual growth rate of Thai output, measured by real GDP in 1988 baht value. Thai output grew at 7.8 percent on average each year with a clear acceleration in 1986, peaking in 1988, and then a gradual decline until 1996. According to the standard growth accounting method, output growth is decomposed into the factor growth and the Solow residual in Figure 1. Factor growth is measured by the sum of growth rates of capital, labor (quality adjusted by taking wage differential across population groups by age, gender, and education), and land (measured by the total area of cultivated land), weighted by their own factor shares. ${ }^{5}$

Factor growth is a major component of the Thai output growth, contributing 5.5 percent out of the total 7.8 percent. Its contribution steadily increases until 1991 (with a noticeably increasing trend after 1986) but begins to decline thereafter. The size of the Solow residual is also substantial, growing at 2.3 percent per year on average. However, Solow residual more closely tracks the fluctuation of output growth. Note in particular that Solow residual surges in 1986, peaks in 1988 like output growth, and then declines to near zero by 1991.

Figure 2 decomposes factor growth into its components. Figures 2.1 and 2.2 display the growth rates and payment shares of the three factors, respectively. Evident from Figure 2.1, capital deepening is the main source of the factor growth. Capital grew at 7.8 percent per year on average, with a sudden acceleration between 1986 and 1991. The annual average growth rates for labor and land were 2.2 percent and 0.8 percent respectively.

Capital share is 55 percent and labor share is 40 percent on average. Both factor shares are fairly stable until 1990, but then capital share decreases while labor share increases. Land share is small ( 5 percent on average) and steadily declines to 2.8 percent by 1996 . Figure 2.3 displays the contribution of each input weighted by its own share to total factor growth. The contribution of land expansion is virtually negligible (0.1 percent on average). Though not negligible, the contribution of labor growth (human-capital augmented via education included) is also small (0.9 percent on average). The main determinant of factor growth in terms of both movement and magnitude is capital deepening (4.5 percent on average).

\section{B Structural Changes}

Thailand provides us with a nationally representative household survey, the Socio-Economic Survey (SES), collected by the National Statistical Office (NSO). Using this micro data, we can measure the two key structural

\footnotetext{
${ }^{5}$ Data Sources for the standard growth accounting are as follows. Gross Domestic Product (GDP) and capital stock: National Economic and Social Development Board (NESDB). Labor employment: Labor Force Survey (LFS). Total area of cultivated land: Ministry of Agriculture and Cooperatives (MOAC). Factor share data: Thailand Development Research Institute (TDRI), documented by Tinakorn and Sussangkarn (1994, 1998). In computing labor income share, Tinakorn and Sussangkarn (1998) use the imputed wage from Social Accounting Matrix (SAM) with base year 1995, rather than the wage from the national income accounts in order to adjust the self-employed income.
} 
changes, occupational transition and financial deepening. ${ }^{6}$

Occupational transition was substantial in Thailand during the sample period, as shown in Figure 3. The fraction of farmers declined monotonically from 55 percent to 31 percent, while the fraction of wageworkers increased from 29 to 50 percent. The non-farm self-employed and employers are categorized as entrepreneurs. Their population share was stable around 15 percent until 1990 and then gradually increased to 19 percent by 1996.

Figure 4 displays three macro financial indicators in Thailand, which are typically used in the study of finance-growth relationship: the ratio of credit claims on private households and the business sector to total domestic credit (PRIVATE), the ratio of credit claims on private households and the business sector to GDP (PRIVY), and the ratio of a broad measure of liquid liabilities, M3, to GDP (LLY). ${ }^{7}$ These indicators suggest that the financial sector has been continually deepened with a non-linear acceleration after the mid-1980's. Note that these macro financial indicators involve financial deepening on both extensive and intensive margins.

The SES records all financial transactions (both borrowing and lending) of each household with all formal financial institutions: commercial banks, savings banks, Bank for Agriculture \& Agricultural Cooperative (BAAC), government housing banks, financial companies, and credit financiers. We count the number of people who actually used the financial institutions from the SES and calculate the fraction of population with access to the financial sector. This represents the extent of access to financial intermediation, which is our measure of "financial deepening." Figure 4 displays this measure, denoted by $p$, again showing a non-linear acceleration in the middle of 1980 's.

This measure of financial deepening $p$ will be exogenously embedded into the model. Obviously, the expansion of intermediation may well involve endogenous participation decisions. Thus, the relevance of the exogeneity assumption depends on whether a significant part of the expansion was indeed driven by exogenous policy reforms. This is indeed the case for Thailand during the period of our analysis. There were several noticeable financial reforms in Thailand initiated around the critical year 1986: 1) liberalization of current and capital account; 2) removal of interest rate controls (preferential lending rates to priority sectors, ceiling rates on deposit and lending); 3) expanding the scope of activities of commercial banks and finance companies (provision of custodial services, information service, financial consulting service, loan syndication, sales of government bonds, relaxation of requirement of portfolio composition, for example, on the minimum required credit to agricultural sector). Another important event that contributed to expanding the extent of the financial sector is the creation of a deposit insurance program, the Financial Institutions Development Fund (FIDF) in 1985, a legal entity under the Bank of Thailand that mandates providing liquidity support to financial institutions.

\footnotetext{
${ }^{6}$ See Jeong (2000) for a detailed description of measurement of these variables from the SES data. Jeong (2006) and Jeong and Townsend (2006) discuss the quantitative importance of these structural changes on growth and inequality in Thailand.

${ }^{7}$ Our labels follow King and Levine (1993). Data Source: Bank of Thailand.
} 
The FIDF was a response to the earlier 1983 financial crisis. ${ }^{8}$

\section{Model}

\section{A Economic Environment}

We consider a model of wealth-constrained occupational choice as in Lloyd-Ellis and Bernhardt (2000), but allow a credit market for a limited group of agents. The economy is populated by a continuum of agents with measure one evolving over discrete time $t=0,1,2 \ldots$ Each agent is endowed with a single unit of time. An agent $i$ with end-of-period wealth $W_{i t}$ at date $t$ maximizes preferences over a single consumption good $c_{i t}$ and wealth carry-over $b_{i, t+1}$ as represented by the utility function

$$
u\left(c_{i t}, b_{i, t+1}\right)=c_{i t}^{1-\omega} b_{i, t+1}^{\omega}
$$

subject to the budget constraint $c_{i t}+b_{i, t+1}=W_{i t}$. The Cobb-Douglas form of preferences implies a linear indirect utility function in $W_{i t}$, making the utility maximization problem equivalent to the end-of-period wealth maximization problem. This form of preferences also implies a linear rule for savings as a constant fraction $\omega$ of wealth. ${ }^{9}$

There are two kinds of production technology, traditional and modern. Using the traditional technology, everyone earns a subsistence return $\gamma$ of the single consumption good. Under the modern technology, entrepreneurs hire capital $k_{t}$ and labor $l_{t}$ at each date $t$ to produce the single consumption good according to production function $f\left(k_{t}, l_{t}\right)$, which is parametrized as quadratic:

$$
f\left(k_{t}, l_{t}\right)=\alpha k_{t}-\frac{\beta}{2} k_{t}^{2}+\xi l_{t}-\frac{\rho}{2} l_{t}^{2}+\sigma l_{t} k_{t}
$$

The quadratic technology adopted here is more flexible than the Cobb-Douglas technology which is a typical specification in macro growth accounting literature. This is intended as a second-order polynomial approximation to any arbitrary production function (including the typical Cobb-Douglas form), and Fuss, McFadden, and Mundlak (1978) show that the quadratic technology is one of the most parsimonious general specifications

\footnotetext{
${ }^{8}$ See Alba, Hernandez and Klingebiel (1999), and Okuda and Mieno (1999) for a detailed discussion of the financial liberalization in Thailand.

${ }^{9}$ Due to the credit constraints, a key feature of the model to be specified, we need to simulate the economy individual by individual, hence the distribution of wealth is an explicit state variable. We also compute transition dynamics, not just steady states, unlike much of the literature. With a long-lived agent setup, we need to solve for Bellman equations individual by individual (as many as in the nationally representative survey data) at conjectured prices, and iterate. Warm-glow preferences save us from this nontrivial computational burden.

The point of our exercise is to merge micro and macro to explain TFP. Thus, the issue is whether the fixed savings rate independent from wealth and talent is important for TFP. Part of those savings might be in anticipation of endogenous entry, selection into the intermediated sector, with the talented more likely to enter. However, from our previous exercise in Jeong and Townsend (2006), we already know that allowing endogenous participation as in Greenwood and Jovanovic (1990) does not generate the observed financial deepening path and hence cannot generate observed TFP dynamics. Talented households under repression seem to have been precluded from entry, so the endogenous dynamics of savings, talent, and selection would not be appropriate for a regulated Thai economy (which then liberalized).
} 
of technology with two factors of production. ${ }^{10}$ This allows time-varying factor shares and more importantly time-varying profitability, which will be shown to play a role in understanding the sources of TFP. ${ }^{11}$ However, note that our quadratic specification is for the individual technology, not for the aggregate one. In fact, we will choose the parameter values to match the observed time-series of aggregate factor shares and hence allow the technology to mimic the Cobb-Douglas form if the aggregate factor shares are indeed constant over time.

There are three occupations, two with the modern technology (entrepreneurs and wageworkers) and one with the traditional technology (self-employed subsisters). The single unit of time is inelastically supplied to the devoted occupation each agent chooses, which determines individual income: profits for modern entrepreneurs, wages for wageworkers, and the subsistence return for traditional self-employed.

There exists a fixed $\operatorname{cost} x_{i t}$ in the wealth unit to start up a business. This is assumed to be independent of the initial wealth level $b_{i t}$ and is randomly drawn from a time-invariant i.i.d. uniform distribution $H$ over the unit interval $[0,1]$, i.e.,

$$
H\left(x_{i t}\right)=x_{i t} \cdot{ }^{12}
$$

The variable $x_{i t}$ is latent and may include any kind of fixed-costs in doing business. Thus there is some degree of freedom in interpreting it. Here, we interpret $x_{i t}$ to represent the inverse of the "entrepreneurial talent" of each agent in a broad sense.

Talent always requires some normalization as it is otherwise not identified. We model the talent for profits in an additive way as in common in the econometrics literature on selection. This additive normalization has many of the same implication as the multiplicative normalization of talent as in Lucas (1978) span of control model. Normalizing talent additively in units of cost (rather than units of output as in multiplicative normalization) facilitates our growth accounting exercise because this separates the effects of financial deepening from those of capital deepening on output growth. (However, again, our growth accounting method that will follow does not depend on this talent specification issue either. $)^{13}$

\footnotetext{
${ }^{10}$ The required number of parameters to represent a technology in the absence of homogeneity restrictions with $n$ factors is $(n+1)(n+2) / 2$, and generalized Leontief, translog, and quadratic forms satisfy this requirement. With dichotomous factors, capital and labor, we need six parameters. Here, we normalize the constant parameter of the quadratic form to zero as this does not matter for growth accounting.

${ }^{11}$ The empirical pattern of constant of factor shares itself seems debatable. Gollin (2002) reports a finding that the employee compensation shares (adjusting self-employed income) are constant mainly across countries and over time for U.S. and U.K. However, Jones (2003) argues that evidence shows that factor shares are clearly not constant over time, even among advanced economies with the only exception of the U.S.

Our growth accounting method and decomposition formula for TFP that will follow do not depend on the functional form of technology.

${ }^{12}$ The time-independence of $x_{i t}$ seems unappealing and it is indeed so if we are interested in tracing the dynamics at individual level. An easy extension allows a fixed effect $\eta_{i}$ in $x_{i t}$ such that $x_{i t}=\eta_{i}+\varepsilon_{i t}$, where $\eta_{i}$ is initially drawn from a uniform distribution and remains constant throughout, $\varepsilon_{i t}$ is a mean-zero i.i.d. shock, and the sum of the lower bounds of $\eta_{i}$ and $\varepsilon_{i t}$ is non-negative. However, it is the i.i.d. component $\varepsilon_{i t}$ rather than the permanent fixed effect $\eta_{i}$ that drives growth dynamics, and the former component is featured in our specification here.

${ }^{13}$ Another implication of this additive specification of talent is that the firm size distribution is generated from the existence of borrowing constraints and hence from the wealth distribution rather than directly from the talent distribution. This paper does not study whether the actual firm size distribtion and its evolution in the data are captured through borrowing constraints and the wealth distribution or through selection based on talent, a subject for futher research.
} 
An agent $i$ is distinguished by a pair of beginning-of-period characteristics: initial wealth $b_{i}$ and randomly drawn entrepreneurial (lack of) talent $x_{i}$. (Due to the recurrent nature of the model, the time subscript is suppressed hereafter unless it is necessary to make it explicit.) There is an additional heterogeneity, depending on their access to intermediation. One group of agents does not have access to credit and has to self-finance both the fixed-cost capital and working capital. They also store their wealth in a backyard with gross return of unity. We call this group the non-credit sector (or sector 1). The second group of agents has access to a credit market, so they can borrow and lend at the equilibrium interest rate of this credit market. We call this group the credit sector (or sector 2). We consider the population fractions of the two sectors to be exogenously determined, matched to the data $p$, as previously discussed. ${ }^{14}$

We intentionally shut down all sources of exogenous technological change, the presumed typical engine of productivity growth in the existing TFP literature. Thus, for us, productivity growth cannot come from technical change but only from improving allocation efficiency, which in turn depends on distribution of wealth and the efficiency of the financial system. Note that occupational shifts in the model are associated with technology adoption, the choice between modern and traditional sectors, hence our model is in the spirit of explaining growth via structural changes as in Hansen and Prescott (2002). However, the driving forces are different: purely financial deepening in our model versus purely technical changes in Hansen and Prescott (2002). We do this not because we think technical change is unimportant, but rather because we would like to see how well the alternative hypothesis of growth based on occupational choice and financial deepening can explain actual growth of output and TFP.

\section{B Non-Credit Sector}

In the non-credit sector, the opportunity cost of capital is determined by a constant return of unity tied to a backyard storage technology. Furthermore, firms must self-finance and face a borrowing constraint:

$$
0 \leq k_{i} \leq b_{i}-x_{i} .
$$

\footnotetext{
${ }^{14}$ In other work of Townsend and Ueda (2006) and Jeong and Townsend (2006), generalizing Greenwood and Jovanovic (1990) model, we have made the entry to the financial sector endogenous, though in a different model which emphasizes the sharing of risk and has fixed transaction costs. That model gets observed Thai trend of financial deepening correct but misses the substantial upturn of the mid-1980. The point is that this is precisely the time that Thailand liberalized the financial system. Thus some (we agree not all) of the deepening and particularly the substantial upturn in mid-1980, are exogenous, due to this policy shift. The spirit of this paper is to see how far we get with that as a driving force. If we linearize the trend of expansion (as it would appear in the endogenous deepening model), the model fails to get the observed upturn in the late 1980s in growth.
} 
Given equilibrium wage $w$, an agent of type $\left(b_{i}, x_{i}\right)$ in sector 1 chooses his occupation to maximize the end-ofperiod wealth $W_{i}$ :

$$
\begin{aligned}
W_{i} & =\gamma+b_{i} \text { for traditional subsisters, } \\
& =w+b_{i} \text { for wageworkers, } \\
& =\pi\left(b_{i}, x_{i}, w\right)+b_{i} \text { for entrepreneurs, }
\end{aligned}
$$

where

$$
\pi\left(b_{i}, x_{i}, w\right)=\max _{k_{i}, l_{i}}\left\{f\left(k_{i}, l_{i}\right)-w l_{i}-k_{i}-x_{i}\right\}^{15} \text { s.t. }(2) .
$$

Note that optimal demands for capital $k_{i}$ and labor $l_{i}$ in the non-credit sector depend on both own wealth $b_{i}$ and talent $x_{i}$ :

$$
\begin{aligned}
k_{i} & =k\left(b_{i}, x_{i}, w\right), \\
l_{i} & =l\left(b_{i}, x_{i}, w\right) .
\end{aligned}
$$

Constraint (2) affects the occupational choice on the extensive margin as well. The higher is the initial wealth $b_{i}$ or the lower the fixed-cost $x_{i}$, the more likely an agent is to become an entrepreneur. However, a potentially efficient, low $x_{i}$, agent may end up being a wageworker, constrained by low initial wealth $b_{i}$. Given wealth $b_{i}$ and market wage $w$, we can define a marginal agent as the one with fixed $\operatorname{cost} x^{m}\left(b_{i}, w\right)$ who is indifferent between being a wageworker and being an entrepreneur, that is $\pi\left(b_{i}, x^{m}, w\right)=w$. If the fixed cost is higher than $x^{m}$, the household will be a wageworker for sure. However, from (2), the fixed cost $x_{i}$ cannot exceed his own wealth $b_{i}$ either. Therefore, given wage $w$ and wealth $b_{i}$, the critical level of fixed cost for the marginal entrant to business is

$$
z\left(b_{i}, w\right)=\min \left[b_{i}, x^{m}\left(b_{i}, w\right)\right] .
$$

With a fixed cost $x_{i}$ less than $z\left(b_{i}, w\right)$, household $i$ chooses to be an entrepreneur.

Figure 5.1 displays an example occupational choice map for the non-credit sector, partitioning the type space $(b, x)$ into four areas: 1) an area of unconstrained subsisters and wageworkers (whose fixed costs are too high, higher than some critical level $z^{*}(w)$, for them to be entrepreneurs regardless of wealth levels), 2) an area of constrained subsisters and wageworkers (whose fixed costs are lower than $z^{*}(w)$ but their wealth levels are not

\footnotetext{
${ }^{15}$ When wealth is used as capital $(k$ and $x)$ in production, it depreciates completely, so $k+x$ is subtracted from profits. This assumption of full depreciation makes the end-of-period wealth and income equivalent. To differentiate between the two, it is enough to add $(1-\delta)(k+x)$ back to the end-of-period-wealth while profits income remains the same. Later we derive growth accounting formula for both output and TFP consistent with this full-depreciation assumption. Incorporating a depreciation rate of less than $100 \%$ can be easily done, maintaining the same formula. For the output growth decomposition, it is enough to replace the gross capital growth with net capital growth. The TFP decomposition formula remains the same.
} 
high enough to self-finance the fixed costs to be entrepreneurs), 3) an area of constrained entrepreneurs (whose fixed costs are low enough and wealth levels high enough to cover the fixed costs, but not sufficient to finance the unconstrained level of working capital), 4) and an area of unconstrained entrepreneurs (whose wealth levels are sufficient to cover both their fixed costs and the unconstrained level of working capital). ${ }^{16}$

Some of the entrepreneurs are constrained in using capital and some are not, but all entrepreneurs earn income higher than or equal to the wageworkers and subsisters. Profits are thus the returns to heterogeneous talent in running business.

\section{Credit Sector}

In the credit sector, the borrowing constraint (2) is dropped, and the cost of capital is an equilibrium gross interest rate $r \geq 1$ that equates the supply and the demand for capital in the credit market. Given equilibrium wage $w$ and gross rate of interest $r$, an agent of type $\left(b_{i}, x_{i}\right)$ in sector 2 chooses his occupation to maximize the end-of-period wealth $W_{i}$ :

$$
\begin{aligned}
W_{i} & =\gamma+r b_{i} \text { for traditional subsisters, } \\
& =w+r b_{i} \text { for wageworkers, } \\
& =\pi\left(b_{i}, x_{i}, w, r\right)+r b_{i} \text { for entrepreneurs, }
\end{aligned}
$$

where

$$
\pi\left(b_{i}, x_{i}, w, r\right)=\max _{k_{i}, l_{i}}\left\{f\left(k_{i}, l_{i}\right)-w l_{i}-r k_{i}-r x_{i}\right\} .
$$

The capital demand $k^{* *}$ of this intermediated sector is given by

$$
k^{* *}(w, r)=\max \left\{\frac{\rho(\alpha-r)+\sigma(\xi-w)}{\rho \beta-\sigma^{2}}, 0\right\}
$$

and the labor demand $l^{* *}$ by

$$
l^{* *}(w, r)=\frac{\xi-w}{\rho}+\frac{\sigma}{\rho} k^{* *}(w, r) .
$$

Every firm hires the same level of capital and labor, $k^{* *}$ and $l^{* *}$. Thus, unlike the first non-credit sector, firm size does not vary over wealth in the credit sector, measured by either capital or labor. However, entrepreneurs still earn differential profits due to differences in individual talent.

Occupational choice in the credit sector is entirely determined by talent and not by individual wealth. The critical level of fixed $\operatorname{cost} z^{* *}(w, r)$ is found by equating unconstrained profits with wage, i.e.,

$$
w=f\left(k^{* *}(w, r), l^{* *}(w, r)\right)-w l^{* *}(w, r)-r k^{* *}(w, r)-r z^{* *}(w, r),
$$

\footnotetext{
${ }^{16}$ See Jeong and Townsend (2006) for detailed characterization of this occupational choice map.
} 
that is,

$$
z^{* *}(w, r)=\frac{1}{r}\left[f\left(k^{* *}(w, r), l^{* *}(w, r)\right)-w l^{* *}(w, r)-r k^{* *}(w, r)-w\right] .
$$

An agent, whose $x_{i}$ is less than $z^{* *}(w, r)$, will establish a firm and earn profits

$$
\pi^{* *}\left(x_{i}, w, r\right)=f\left(k^{* *}(w, r), l^{* *}(w, r)\right)-w l^{* *}(w, r)-r k^{* *}(w, r)-r x_{i} .
$$

Figure 5.2 displays an example occupational choice map for the credit sector, partitioning the type space $(b, x)$ into two areas: an area of subsisters and wageworkers and an area of entrepreneurs. Both groups are unconstrained in their occupational choices. Entrepreneurs are again the agents who are more efficient in running business and earn the rents to their talents in the form of profits. Hence, entrepreneurial income is higher than or equal to wage income. However, here, neither the distribution nor the accumulation of wealth play any direct role in occupational choice. Occupational choice dynamics are determined only by factor price dynamics through $z^{* *}(w, r)$. Furthermore, wage growth reduces entrepreneurship in the credit sector (while the same wage growth fosters entrepreneurship in the non-credit sector).

\section{Competitive Equilibrium}

The two sectors are combined in one model with an exogenously expanding credit sector by embedding the Thai population fraction of the credit sector, i.e., $p$, shown in Figure 4. Given the exogenous path $p$, and initial wealth distributions of non-credit and credit sectors $\left(\Psi_{10}, \Psi_{20}\right)$, a competitive equilibrium is defined such that:

1. Given wage $w_{t}$ and interest rate $r_{t}$ at date $t$, each agent of type $\left(b_{i t}, x_{i t}\right)$ chooses his or her occupation to maximize utility. If the agent chooses to be an entrepreneur, he or she chooses demands for capital and labor that maximize profits;

2. Labor market clears for the entire economy:

$$
\left(1-p_{t}\right) \sum_{k=s, w, e} \Phi_{1}^{k}\left(w_{t}, \Psi_{1 t}\right)+p_{t} \sum_{k=s, w, e} \Phi_{2}^{k}\left(w_{t}, r_{t}\right)=1
$$

where $p_{t}$ denotes the population fraction of the credit sector at date $t$ and $\Phi_{j}^{k}$ the population fraction of occupation $k$ of sector $j$, for $k=s$ (subsisters), $w$ (wageworkers), and $e$ (entrepreneurs), and $j=1,2$;

3. Capital market clears for the credit sector:

$$
K_{2}^{m}\left(w_{t}, r_{t}\right)+X_{2}\left(w_{t}, r_{t}\right)=K_{2 t},
$$

where $K_{2}^{m}\left(w_{t}, r_{t}\right)$ and $X_{2}\left(w_{t}, r_{t}\right)$ denote the aggregate demands for working capital and fixed-cost capital, and $K_{2 t}$ the aggregate supply of capital, (which is the aggregate beginning-of-period of wealth $B_{2 t}$.) 


\section{Aggregate Dynamics}

\section{A Aggregate Production Function}

An aggregate production function is defined as a mapping $F$ from aggregate inputs $K$ and $L$ to aggregate output $Y$. But the production function $f$ in the model here is about individual technologies. We discuss whether an aggregate production function can be derived from the individual technologies $f$. Since each agent can be identified by a pair of own wealth and entrepreneurial talent $(b, x)$, we drop the individual index $i$ here. ${ }^{17}$

In the credit sector at date $t$, an agent $(b, x)$ whose $x$ is lower than $z^{* *}\left(w_{t}, r_{t}\right)$ chooses to run a firm, employing optimal amount of capital and labor $k^{* *}\left(w_{t}, r_{t}\right)$ and $l^{* *}\left(w_{t}, r_{t}\right)$ in (10) and (11) and produces output $y_{2 t}(b, x)=f\left[k^{* *}\left(w_{t}, r_{t}\right), l^{* *}\left(w_{t}, r_{t}\right)\right]$. We can get aggregate output of the credit sector $Y_{2 t}^{m}$ from these firms by integrating the individual output over the type space $(b, x)$, where $x$ is less than the critical value $z^{* *}\left(w_{t}, r_{t}\right)$ :

$$
Y_{2 t}^{m}=\int_{0}^{\infty} \int_{0}^{z^{* *}\left(w_{t}, r_{t}\right)} y_{2 t}(b, x) d H(x) d \Psi_{2 t}(b),
$$

where $H$ and $\Psi_{2 t}$ are the distribution functions for $x$ and $b$ in the credit sector. Note that both the optimal factor demands, $k^{* *}$ and $l^{* *}$, and the critical value of talent $z^{* *}$ are free from individual wealth. This makes aggregation straightforward, and the aggregate production function is well-defined:

$$
\begin{aligned}
Y_{2 t}^{m} & =\int_{0}^{\infty} \int_{0}^{z^{* *}\left(w_{t}, r_{t}\right)} f\left[k^{* *}\left(w_{t}, r_{t}\right), l^{* *}\left(w_{t}, r_{t}\right)\right] d H(x) d \Psi_{2 t}(b) \\
& =\int_{0}^{\infty} \int_{0}^{z^{* *}\left(w_{t}, r_{t}\right)} d H(x) d \Psi_{2 t}(b) f\left[k^{* *}\left(w_{t}, r_{t}\right), l^{* *}\left(w_{t}, r_{t}\right)\right] \\
& =\Phi_{2}^{e}\left(w_{t}, r_{t}\right) f\left[k^{* *}\left(w_{t}, r_{t}\right), l^{* *}\left(w_{t}, r_{t}\right)\right] \\
& =G_{2}\left(w_{t}, r_{t}\right)
\end{aligned}
$$

where $\Phi_{2}^{e}\left(w_{t}, r_{t}\right)$ denotes the population fraction of entrepreneurs in the credit sector. Thus, when the individual agents have access to a perfect credit market, the individual production function $f$ translates into an aggregate production function, free of the wealth distribution. Only factor prices matter for output and the fraction of entrepreneurs $\Phi_{2}^{e}\left(w_{t}, r_{t}\right)$ appears as the TFP term.

Aggregate output in the non-credit sector $Y_{1 t}^{m}$ is obtained as follows:

$$
\begin{aligned}
Y_{1 t}^{m} & =\int_{0}^{\infty} \int_{0}^{z\left(b, w_{t}\right)} f\left[k\left(b, x, w_{t}\right), l\left(b, x, w_{t}\right)\right] d H(x) d \Psi_{1 t}(b) \\
& =G_{1}\left(w_{t} ; \Psi_{1 t}\right)
\end{aligned}
$$

where $H$ and $\Psi_{1 t}$ are the distribution functions for $x$ and $b$ in the non-credit sector. Here, factor demands $k\left(b, x, w_{t}\right)$ and $l\left(b, x, w_{t}\right)$ depend on both wealth and talent. The critical value $z\left(b, w_{t}\right)$, below which agents

\footnotetext{
${ }^{17}$ The aggregate production function for the traditional technology is obviously well-defined regardless of access to credit due to its linear nature and we will focus only on the modern technology.
} 
choose to be entrepreneurs, also depends on wealth and we cannot disentangle the wealth distribution and the talent distribution from each other. That is, we cannot get a representation of aggregate output in terms of aggregate inputs. The wealth distribution $\Psi_{1 t}$ itself enters as a state variable of the aggregate production function, as expressed in (19). Thus, the interaction between factor price dynamics and the evolution of wealth distribution plays a key role in determining the aggregate dynamics of output and TFP when there is no intermediation.

The economy-wide aggregate production from modern technology $Y_{t}^{m}$ can be obtained from the weighted sum of $Y_{1 t}^{m}$ and $Y_{2 t}^{m}$,

$$
\begin{aligned}
Y_{t}^{m} & =\left(1-p_{t}\right) Y_{1 t}^{m}+p_{t} Y_{2 t}^{m} \\
& =\left(1-p_{t}\right) G_{1}\left(w_{t} ; \Psi_{1 t}\right)+p_{t} G_{2}\left(w_{t}, r_{t}\right) \\
& =F\left(w_{t}, r_{t}, \Psi_{1 t}, p_{t}\right)
\end{aligned}
$$

That is, aggregate output $Y_{t}^{m}$ is determined by equilibrium prices $w_{t}$ and $r_{t}$, wealth distribution of the non-credit sector $\Psi_{1 t}$, and level of financial deepening $p_{t}$.

\section{B Take-Off Wage Dynamics}

The model has the well-known take-off feature of the dual-economy models, pioneered by Lewis (1954) and Ranis and Fei (1961), where there exists surplus labor in the traditional sector and wage stays constant, then picks up after some critical point in time with a exhaustion of surplus labor. ${ }^{18}$ The subsistence income $\gamma$ plays the role of a reservation wage $\underline{w}$, below which every potential wageworker prefers to remain in traditional technology. Likewise, if the wage exceeds the reservation wage level, no one remains in traditional technology. The population proportions of wageworkers and subsistence self-employed are determined by the demand for labor from the modern technology. When the labor demand of the modern entrepreneurs is not strong enough, the traditional subsisters (which may be termed surplus labor) coexist with the modern wageworkers, and the equilibrium wage is tied to the constant subsistence income $\gamma$. As the economy grows and demand for labor from the modern entrepreneurs becomes strong enough, the wage starts to grow beyond $\gamma$ and traditional subsisters vanish. Thus, wage shows the take-off feature in equilibrium.

Note that we do not rely on the assumption of the typical dual-economy models, i.e., asymmetry in marginal productivity of labor between modern and traditional sectors. In our model, the marginal productivity of labor is endogenously determined and equalized (and positive) between the two technologies when they coexist, but we still can generate the take-off feature of wage dynamics. Asymmetry in the returns to capital, instead of labor, may play a more important role in the development of the dual economy, as the model suggests.

\footnotetext{
${ }^{18}$ Ranis and Fei (1961) call it a "commercialization point."
} 


\section{Entrepreneurship}

Financial deepening does not necessarily promote entrepreneurship for the entire economy. There are direct and indirect effects of financial deepening on entrepreneurship. The direct effect is related to the change in the weights of the two sectors in the aggregate economy. Financial deepening also affects entrepreneurship indirectly through the changes in factor prices, which has different impacts on the two sectors. The overall direction and size of each effect of financial deepening on entrepreneurship, direct or indirect, depends on the wealth distribution and factor prices.

First, financial deepening gives more weight to the credit sector in the aggregate economy. Access to credit helps poor people to relax the borrowing constraint on their occupational choices, encouraging the poor talented people to become entrepreneurs. Hence the fraction of entrepreneurs is larger in the credit sector than in the non-credit sector among poor people. Two occupational choice maps (Figures 5.1 and 5.2) at the wealth

levels lower than $\widehat{b}$, for example, make this point clear. However, among rich people who do not face borrowing constraints, the incentive to become entrepreneurs is less in the credit sector than the non-credit sector because credit-sector agents, when they are not talented, deposit their wealth in banks, earning a positive net return from the deposit as well as a wage. A comparison of Figures 5.1 and 5.2 at the wealth levels exceeding $b^{*}$, where occupational choices are unconstrained in both sectors, makes this point. In fact, the critical level of fixed cost that determines the extensive margin between unconstrained wageworkers and unconstrained entrepreneurs is always lower in the credit sector than in the non-credit sector, i.e.,

$$
z^{* *}(w, r) \leq z^{*}(w), \text { for each } w \text { and } r \geq 1,
$$

and the gap $z^{*}(w)-z^{* *}(w, r)$ increases in $r$ for every given wage $w \cdot{ }^{19}$ Thus, in the region of high wealth, the fraction of entrepreneurs is lower in the credit sector than in the non-credit sector. In sum, when the wealth distribution is concentrated toward the lower tail or when the interest rate is low, financial deepening is likely to increase the aggregate fraction of entrepreneurs, but for a wealthy and high-interest economy, financial

\footnotetext{
monotonically decreasing in $r$, which is proved as follows. From (12),

$$
z^{* *}(w, r)=\frac{g(w, r)}{r}
$$

where

Thus,

$$
g(w, r)=f\left(k^{* *}(w, r), l^{* *}(w, r)\right)-w l^{* *}(w, r)-r k^{* *}(w, r)-w
$$

$$
\begin{aligned}
\frac{\partial z^{* *}(w, r)}{\partial r} & =\frac{\frac{\partial g(w, r)}{\partial r}}{r}-\frac{g(w, r)}{r^{2}} \\
& =\frac{\frac{\partial g(w, r)}{\partial r}}{r}-\frac{r z^{* *}(w, r)}{r^{2}} \\
& =\frac{1}{r}\left[\frac{\partial g(w, r)}{\partial r}-z^{* *}(w, r)\right]
\end{aligned}
$$
}

${ }^{19}$ First, note that the wage $w$ is common to both sectors and the difference regarding the critical values of setup cost between the two sectors comes from the difference in opportunity cost of capital, which is an interest rate $r \geq 1$ for credit sector but a unity for non-credit sector. Second, it is easy to check that $z^{* *}(w, r)=z^{*}(w)$ when $r=1$. Thus, it is enough to show that $z^{* *}(w, r)$ is a 
deepening is likely to reduce it. In other words, the expansion of access to intermediation may promote or diminish entrepreneurship, depending on the wealth distribution and factor prices.

Second, recall that the model implies a take-off feature of wage dynamics. Financial deepening through employment fosters wage growth. The wage growth is common to both credit and non-credit sectors, but the response to the wage growth is different between the two sectors. Within the non-credit sector, wage growth helps wealth accumulation for poor wageworkers, and possibly (depending on the magnitude of the wage growth) encourages the more talented among them to switch their occupation into entrepreneurs. This improves allocation efficiency. In the credit sector, occupational choices are already efficient and occupational shifts depend only on the movement of factor prices. An increase in wage reduces profits, and hence the fraction of entrepreneurs in the credit sector: $z^{* *}(w, r)$ and $\pi^{* *}(x, w, r)$ are both decreasing in wage $w$, from the Envelope theorem. Thus, there are counteracting effects of wage growth on entrepreneurship and overall productivity growth.

\section{Simulation}

\section{A Calibration}

The above discussion shows that there are various general equilibrium forces that interact with each other in determining aggregate dynamics. Thus, the model is simulated to see whether it can generate the observed aggregate dynamics when aligned to the actual Thai data. We first select the parameters of the model that best fit the aggregate data of Thailand in terms of the savings rate, output growth rate, and factor shares. The initial wealth distribution and the financial deepening measure are obtained from the micro data, the Thai Socio-Economic Survey.

The preference parameter $\omega$ corresponds to the propensity to save and is calibrated at 0.3 to match the average savings rate in the national income accounts of Thailand between 1976 and 1996. The subsistence return parameter $\gamma$ is calibrated to match the SES 1976 annual household wage payment, 190,000 baht. Here, we suppose the 1976 Thai wage to be close to the reservation wage and hence subsistence income $(\underline{w}=\gamma)$ in the model. During 1976-1986, the fraction of farmers went down from $55 \%$ to $31 \%$ while the fraction of wageworkers increased from $29 \%$ to $50 \%$. (See Figure 3.) But the Thai wage stayed constant during this period. According to the model, compositional change between wageworkers and subsisters with a constant wage can only happen

Since we know that $z^{* *}(w, r) \geq 0$, it is enough to show that the derivative $\frac{\partial g(w, r)}{\partial r}$ is negative, which can be shown:

$$
\begin{aligned}
\frac{\partial g(w, r)}{\partial r} & =f_{k}\left(k^{* *}, l^{* *}\right) \frac{\partial k^{* *}(w, r)}{\partial r}+f_{l}\left(k^{* *}, l^{* *}\right) \frac{\partial l^{* *}(w, r)}{\partial r}-w \frac{\partial l^{* *}(w, r)}{\partial r}-k^{* *}(w, r)-r \frac{\partial k^{* *}(w, r)}{\partial r} \\
& =\left[f_{k}\left(k^{* *}, l^{* *}\right)-r\right] \frac{\partial k^{* *}(w, r)}{\partial r}+\left[f_{l}\left(k^{* *}, l^{* *}\right)-r\right] \frac{\partial l^{* *}(w, r)}{\partial r}-k^{* *}(w, r) \\
& =-k^{* *}(w, r) \leq 0 .
\end{aligned}
$$

The final equality comes from the Envelope Theorem. 
at the reservation wage. Thus the approximation of $\gamma$ by the 1976 wage seems reasonable.

We need to choose a scale parameter $s$ that converts the Thai baht unit into the model income unit. The subsistence parameter $\gamma$ is re-scaled using the scale parameter. To be consistent, the Thai initial wealth distribution is put into the model using the same scale. Given the bounded support and additive nature of the fixed cost $x$ and the borrowing constraint in (2), the choice of scale is important for the growth dynamics of the model, not only through the value of $\gamma$ but also through the scale of initial wealth distribution.

Conditional on the chosen values of $\omega$ and $\gamma$, the technology parameters $\alpha, \beta, \xi, \rho, \sigma$, and the scale parameter $s$ are calibrated to match the key aggregate objects in the standard growth accounting formula, i.e., the paths of GDP growth rate and labor share in Thailand for the period of 1976-1996, using an explicit root-mean-squared-error (RMSE) criterion (the two variables being equally weighted). Table 1 summarizes the selected parameters.

Table 1. Model Parameters

\begin{tabular}{|cccccccc|}
\hline$\omega$ & $\gamma$ & $s$ & $\alpha$ & $\beta$ & $\xi$ & $\rho$ & $\sigma$ \\
\hline 0.3000 & 0.0190 & $10^{-7}$ & 1.1111 & 0.0010 & 0.1000 & 0.0063 & 0.0000 \\
\hline
\end{tabular}

Here, we choose parameter values to match the time-series of total output growth and labor share but not the input growth. Hence, we are not matching TFP. In other work of Jeong and Townsend (2006), we do not calibrate against observed growth at all. Rather, we estimate the parameters using maximum likelihood methods on individual occupational choice and yet these parameter values yield simulation and decomposition results for TFP similar to our benchmark calibration here.

\section{B Simulated Aggregate Dynamics}

The simulated economy tracks Thai output growth and labor share reasonably well, as shown in Figures 6.1 and 6.2. Simulated annual growth is a little lower than in the actual Thai data. The model misses some engines of growth in Thailand. However, the dynamic patterns of Thai growth, the slow-down in early 1980's, the surge after 1986, and the continual decline thereafter, are all well captured by the model. Simulated labor share is also a little lower than in the Thai data, but again the model captures dynamic patterns, such as the upturn of the labor share after 1990 in the data. The upturn is mainly due to wage growth rather than the change in employment, both in the model and the data. Indeed the model performs very well in predicting the take-off feature of wage dynamics, as observed in Thailand, shown in Figure $6.3 .^{20}$ The Thai (full-time) wage had been flat for a decade despite fast growth, but then this was followed by a sudden and continued growth.

\footnotetext{
${ }^{20}$ The Thai wage is measured by the average wage income of full-time wage-earning households, excluding part-time wage income. Thus, it does not represent average wage earnings in the national income accounts. A substantial part of wage payments in Thailand during the sample period comes from part-time wage earners but the population fraction of the part-time wage earners decreases over time. Given the big difference in wages between full-time and part-time workers, total wage payments measured in national income grow with output growth. Thus, we have a more or less constant aggregate labor share in Figure 6.2 and a flat (full-time) wage in Figure 6.3 during the first decade.
} 
The simulated fraction of entrepreneurs, shown in Figure 6.4, increases from 1.5 to 8.4 percent, with acceleration in 1986 when the rate of financial deepening accelerates. The fraction of entrepreneurs in the model is lower than the data and the gap is large, when the category of entrepreneurs in the data includes both employer and self-employed in non-agriculture (labeled as "Thai Broad" in Figure 6.4). The "Thai Broad" category of entrepreneurs stays constant around 15 percent, and only after 1990 does it begin to rise, reaching 19 percent by 1996. When we restrict the data to employers only (labeled as "Thai Narrow" in Figure 6.4), the model exceeds the rate in the data. The rate of the narrow category increased from 1.4 percent to 3.7 percent, with a substantial rise again after 1990. Both the narrow and broad categories in the data behave similarly over time. Here, we focus on the broad category with a view to identifying the occupation of entrepreneurs as one which generates profits.

The model predicts Thai TFP growth well. As shown in Figure 6.5, simulated TFP growth tracks quite closely actual Thai TFP growth, in terms of both magnitude and movement.

\section{Decomposition of TFP Growth}

\section{A Decomposition Method}

\section{A.1 Aggregation}

From equations (4) and (9), output produced by a modern entrepreneur $i$ in sector $j, j=1,2$, is given by

$$
y_{i j}^{m}=w l_{i j}^{m}+r_{j} k_{i j}^{m}+r_{j} x_{i j}+\pi_{i j}
$$

where $y_{i j}^{m}, l_{i j}^{m}, k_{i j}^{m}$, and $x_{i j}$ denote output, labor, working capital, and fixed-cost capital, and $r_{j}=1$ for $j=1$ (non-credit sector) and $r_{j}=r$ for $j=2$ (credit sector). Total output $Y_{j}^{m}$ in sector $j$ from the modern technology is obtained by integrating $y_{i j}^{m}$ over type $\left(b_{i}, x_{i}\right)$, consistent with occupational choices:

$$
Y_{j}^{m}=w L_{j}^{m}+r_{j} K_{j}^{m}+r_{j} X_{j}+\Pi_{j}, \text { for } j=1,2
$$


where

$$
\begin{aligned}
L_{1}^{m} & =\int_{0}^{\infty} \int_{0}^{z(b, w)} l(b, x, w) d H(x) d \Psi_{1}(b), \\
L_{2}^{m} & =\int_{0}^{z^{* *}(w, r)} l^{* *}(w, r) d H(x), \\
K_{1}^{m} & =\int_{0}^{\infty} \int_{0}^{z(b, w)} k(b, x, w) d H(x) d \Psi_{1}(b), \\
K_{2}^{m} & =\int_{0}^{z^{* *}(w, r)} k^{* *}(w, r) d H(x), \\
X_{1} & =\int_{0}^{z(b, w)} x d H(x), \\
X_{2} & =\int_{0}^{z^{* *}(w, r)} x d H(x), \\
\Pi_{1} & =\int_{0}^{\infty} \int_{0}^{z(b, w)} \pi(b, x, w) d H(x) d \Psi_{1}(b), \\
\Pi_{2} & =\int_{0}^{z^{* *}(w, r)} \pi^{* *}(x, w, r) d H(x) .
\end{aligned}
$$

Equation (20) expresses a version of the usual income-payment approach: output produced by firms in sector $j$ is decomposed into payments to labor $w L_{j}^{m}$, to working capital $r_{j} K_{j}^{m}$, fixed-cost capital $r_{j} X_{j}$ plus profits $\Pi_{j}$. Note that occupational choice based on differential entrepreneurial talent makes realized profit higher than or equal to wage for every entrepreneur. Thus, overall profits are positive.

Total output from the traditional technology in sector $j$ is

$$
Y_{j}^{s}=\gamma \Phi_{j}^{s}, \text { for } j=1,2
$$

where $\Phi_{j}^{s}$ denotes the population fraction of subsisters in sector $j$.

There remains the third implicit technology, i.e., savings or storage technology. In the non-credit sector, agents save left-over wealth, not used by firms, in the backyard storage technology at the constant return of unity, and aggregate income from this storage technology can be expressed as

$$
Y_{1}^{b}=K_{1}-K_{1}^{m}-X_{1}
$$

where $K_{1}$ denotes the total capital supply in sector 1 . In the credit sector, agents who have left-over wealth will deposit it in the bank earning financial income, and agents who have excess demand for capital will borrow from the bank. Thus, aggregate financial income from banks is

$$
Y_{2}^{b}=r\left(K_{2}-K_{2}^{m}-X_{2}\right)
$$

where $K_{2}$ denotes the total capital supply in sector 2. Capital market clearing condition in (15) makes the financial income in the credit sector zero in the aggregate. 
Adding up the output from all three sources, we get the total output $Y_{j}$ for sector $j$

$$
\begin{aligned}
Y_{j} & =Y_{j}^{m}+Y_{j}^{s}+Y_{j}^{b} \\
& =w L_{j}^{m}+r_{j} K_{j}^{m}+r_{j} X_{j}+\Pi_{j}+\gamma \Phi_{j}^{s}+r_{j}\left(K_{j}-K_{j}^{m}-X_{j}\right) \\
& =w \Phi_{j}^{w}+\gamma \Phi_{j}^{s}+r_{j} K_{j}+\Pi_{j} \\
& =w L_{j}+r_{j} K_{j}+\Pi_{j}
\end{aligned}
$$

where $L_{j} \equiv \Phi_{j}^{w}+\Phi_{j}^{s}$ denotes the population fraction of non-entrepreneurial labor force in sector $j .{ }^{21}$

\section{A.2 Decomposition}

The main idea of the decomposition of TFP growth is that growth accounting by factor and growth accounting by sector should each yield the same output growth. By equating the two versions, we can identify the sources of aggregate TFP growth in terms of sectoral TFP growth and compositional changes on the two extensive margins: occupational shifts and expansion of the credit sector (our measure of financial deepening).

Growth Accounting by Factor Total output $Y$ can be decomposed into factor payments,

$$
Y=w L+r K+\Pi-(r-1) U,{ }^{22}
$$

where $L$ denotes the total non-entrepreneurial workforce, $K$ the total capital, $\Pi$ the total profits, and $U$ the total unintermediated capital, i.e.,

$$
U \equiv(1-p) K_{1}
$$

This income accounting identity differs from the standard one for two reasons. First, profit income $\Pi$ is explicitly separated out. Second, there is an adjustment term $-(r-1) U$. This adjustment is due to the difference in cost of capital between credit and non-credit sectors. In the income accounting equation (23), the entire capital $K$ is priced at the interest rate $r$, while $r$ is the cost of capital only for the credit sector. In the non-credit sector, a gross return of unity is the correct opportunity cost of capital. The adjustment term $-(r-1) U$ corrects this mis-measurement of capital income. If the national income accounts precisely measured the rental income of capital using the true opportunity cost of capital, explicitly reflecting differential access to credit, this adjustment term would vanish.

\footnotetext{
${ }^{21}$ Total labor demand from firms $L_{j}^{m}$ equals population fraction of wageworkers $\Phi_{j}^{w}$. When both traditional and modern technologies coexist, the wage is set to reservation wage at $\underline{w}=\gamma$, and hence $w \Phi_{j}^{w}+\Phi_{j}^{s} \gamma=w\left(\Phi_{j}^{w}+\Phi_{j}^{s}\right)=w L_{j}$. When the wage starts to grow, $w>\gamma$ but traditional sector vanishes, i.e., $\Phi_{j}^{s}=0$ so that we still can write $w \Phi_{j}^{w}+\Phi_{j}^{s} \gamma=w L_{j}$.

${ }^{22}$ Note that gross interest rate $r$ is used in (23), due to the assumption of complete depreciation of capital. Recall the profit equations (4) and (9). To incorporate a depreciation rate of capital $\delta$ different from one, it is enough to replace $r$ by $(r-1+\delta)$ in (23). All formulae of growth accounting will remain same.
} 
From the income accounting identity (23), we get a growth accounting by factor ${ }^{23}$ :

$$
g_{Y}=s_{L}\left(g_{L}+g_{w}\right)+s_{K}\left(g_{K}+g_{r}\right)+s_{\Pi} g_{\Pi}-s_{U}\left(g_{U}+\left(\frac{r}{r-1}\right) g_{r}\right),
$$

where

$$
s_{L}=\frac{w L}{Y}, s_{K}=\frac{r K}{Y}, s_{U}=\frac{(r-1) U}{Y}, s_{\Pi}=\frac{\Pi}{Y},
$$

and $g_{V}$ denotes the growth rate of variable $V \cdot{ }^{24}$ Output growth is decomposed into growth of input quantities and growth of input prices, each weighted by appropriate factor shares. TFP growth, hereafter denoted by $T F P G$, is defined as is standard as the difference between the output growth and the weighted sum of input quantities growth:

$$
T F P G \equiv g_{Y}-\left(s_{K} g_{K}-s_{U} g_{U}\right)-s_{L} g_{L}
$$

Note that TFPG incorporates two kinds of heterogeneity. ${ }^{25}$ First, the term $s_{U} g_{U}$ captures the effect of the compositional change in heterogenous types of capital between the intermediated and unintermediated sectors. Second, the same unit of time can be devoted to different occupations, which generates heterogeneity in labor. Through self-selection based on entrepreneurial talent, entrepreneurs always earn income higher than or equal to wageworkers and subsisters using the same unit of time and wealth. Thus, a decrease in the population

${ }^{23}$ Differentiating both sides of (23) with respect to time and then dividing by $Y$, we get

$$
\begin{aligned}
\frac{\dot{Y}}{Y} & =\frac{\dot{w} L}{Y}+\frac{w \dot{L}}{Y}+\frac{\dot{r} K}{Y}+\frac{r \dot{K}}{Y}+\frac{\dot{\Pi}}{Y}-\frac{\dot{r} U}{Y}-\frac{r \dot{U}}{Y}+\frac{\dot{U}}{Y}+\frac{\dot{U}}{Y} \\
& =\frac{\dot{w}}{w} \frac{w L}{Y}+\frac{\dot{L}}{L} \frac{w L}{Y}+\frac{\dot{r}}{r} \frac{r K}{Y}+\frac{\dot{K}}{K} \frac{r K}{Y}+\frac{\dot{\Pi}}{\Pi} \frac{\Pi}{Y}-\frac{\dot{r}}{r} \frac{r U}{Y}-\frac{\dot{U}}{U} \frac{(r-1) U}{Y}
\end{aligned}
$$

where the upper dot denotes a time derivative, e.g., $\dot{Y} \equiv \frac{d Y}{d t}$, hence $\frac{\dot{Y}}{Y}$ indicates the growth rate of $Y$.

${ }^{24}$ The growth accounting formula in $(25)$ is written as a growth rate of Divisia index in continuous time. In practice, with discrete-time data, we use the following decomposition formula between initial period $s$ and final period $t$ :

$$
\begin{aligned}
g_{Y}= & \frac{\bar{w} L_{s}}{Y_{s}} g_{L}+\frac{w_{s} \bar{L}}{Y_{s}} g_{w}+\frac{\bar{r} K_{s}}{Y_{s}} g_{K}+\frac{r_{s} \bar{K}}{Y_{s}} g_{r} \\
& +\frac{\Pi_{s}}{Y_{s}} g_{\Pi}-\frac{\bar{r} U_{s}}{Y_{s}} g_{U}-\frac{r_{s} \bar{U}}{Y_{s}} g_{r},
\end{aligned}
$$

where the upper bar denotes the average between periods $s$ and $t$. Note that this formula is similar to the Tornqvist approximation (that uses average of factor shares between dates) to the Divisia index, but our formula for discrete data is an exact decomposition rather than an approximation. Hereafter, we apply this discrete version of decomposition formula to all the following accounting identities.

${ }^{25}$ In "standard" growth accounting, the Solow residual $S R$ (in per capita term) is measured by the difference between the output growth rate $g_{Y}$ and the capital growth rate $g_{K}$, weighted by capital share $s_{K}=\frac{r K}{Y}$ :

$$
S R \equiv g_{Y}-s_{K} g_{K} .
$$

Thus, the standard Solow residual potentially diverges from our measure of TFP growth by two sources, $-s_{L} g_{L}$ (adjustment for labor heterogeneity) and $s_{U} g_{U}$ (adjustment for capital heterogeneity):

$$
T F P G-S R=-s_{L} g_{L}+s_{U} g_{U} .
$$

When capital and labor are homogeneous (i.e., when there are no occupational choices and everyone has equal access to credit), the standard Solow residual coincides with the TFP growth in (27). 
fraction of wageworkers and subsisters toward entrepreneurs increases $T F P .{ }^{26}$ The term $-s_{L} g_{L}$ captures this effect.

Rearranging the TFP growth formula (27), we get

$$
g_{Y}=T F P G+s_{L} g_{L}+s_{K} g_{K}-s_{U} g_{U} .
$$

The growth rates of aggregate factors $g_{L}, g_{K}$, and $g_{U}$ can be further decomposed into sectoral levels:

$$
\begin{aligned}
g_{L} & =\widetilde{s}_{L_{1}}(1-p) g_{L_{1}}+\widetilde{s}_{L_{2}} p g_{L_{2}}+\left(\widetilde{s}_{L_{2}}-\widetilde{s}_{L_{1}}\right) p g_{p} \\
g_{K} & =\widetilde{s}_{K_{1}}(1-p) g_{K_{1}}+\widetilde{s}_{K_{2}} p g_{K_{2}}+\left(\widetilde{s}_{K_{2}}-\widetilde{s}_{K_{1}}\right) p g_{p} \\
g_{U} & =g_{K_{1}}-\frac{1}{1-p} p g_{p} .
\end{aligned}
$$

where $\widetilde{s}_{L_{j}}=\frac{L_{j}}{L}$ and $\widetilde{s}_{K_{j}}=\frac{K_{j}}{K} \cdot{ }^{27}$ Substituting equations (29) to (31) into the aggregate factor growth equation (28), we get

$$
g_{Y}=T F P G+\left[\widetilde{s}_{Y_{2}}\left(s_{L_{2}}+s_{K_{2}}\right)-\widetilde{s}_{Y_{1}}\left(s_{L_{1}}+s_{K_{1}}\right)\right] p g_{p}+(1-p) \widetilde{s}_{Y_{1}}\left(s_{L_{1}} g_{L_{1}}+s_{K_{1}} g_{K_{1}}\right)+p \widetilde{s}_{Y_{2}}\left(s_{L_{2}} g_{L_{2}}+s_{K_{2}} g_{K_{2}}\right) .
$$

Growth Accounting by Sector Economy-wide output $Y$ is a weighted sum of sectoral outputs $Y_{1}$ and $Y_{2}$,

$$
Y=(1-p) Y_{1}+p Y_{2}
$$

where $p$ is the population fraction of the credit sector. This gives a growth accounting identity by sector:

$$
g_{Y}=(1-p) \widetilde{s}_{Y_{1}} g_{Y_{1}}+p \widetilde{s}_{Y_{2}} g_{Y_{2}}+\left(\widetilde{s}_{Y_{2}}-\widetilde{s}_{Y_{1}}\right) p g_{p}
$$

where $\widetilde{s}_{Y j}=\frac{Y_{j}}{Y}$. Within-sector output growth $g_{Y_{j}}$ can be expressed:

$$
g_{Y_{j}}=T F P G_{j}+s_{L_{j}} g_{L_{j}}+s_{K_{j}} g_{K_{j}}, \text { for } j=1,2,
$$

where $s_{L_{j}}=\frac{w L_{j}}{Y_{j}}$ and $s_{K_{j}}=\frac{r_{j} K_{j}}{Y_{j}}$, and $T F P G_{j}$ denotes intra-sectoral TFP growth of sector $j$. Substituting the within-sector growth rates $g_{Y_{1}}$ and $g_{Y_{2}}$ as in (35) into (34), we get

$$
\begin{aligned}
g_{Y}= & \left(\widetilde{s}_{Y_{2}}-\widetilde{s}_{Y_{1}}\right) p g_{p}+(1-p) \widetilde{s}_{Y_{1}} T F P G_{1}+p \widetilde{s}_{Y_{2}} T F P G_{2} \\
& +(1-p) \widetilde{s}_{Y_{1}}\left(s_{L_{1}} g_{L_{1}}+s_{K_{1}} g_{K_{1}}\right)+p \widetilde{s}_{Y_{2}}\left(s_{L_{2}} g_{L_{2}}+s_{K_{2}} g_{K_{2}}\right) .
\end{aligned}
$$

\footnotetext{
${ }^{26} \mathrm{TFP}$ growth from this occupational shift is indeed an efficiency gain in the non-credit sector because the occupational shift reflects the relaxation of constraints on the extensive margin. However, there is a subtle difference between TFP growth and efficiency improvements in the credit sector. Occupational choices in the credit sector are already efficient and the compositional change in occupation is a pure response to factor price movements (again efficiently selected over talents). Thus, unlike the non-credit sector, there is no net efficiency gain from occupational shifts in the credit sector. However, output can grow from the occupational shift at given endowments of wealth and time and this appears TFP growth. This point was explicitly made previously in equation (16). Recall that the population size is normalized to one and everyone is in the work force providing one unit of time inelastically. Thus, this term is related neither to changes in labor force participation nor to the changes in hours of work.

${ }^{27}$ This is obtained from the aggregation identities for sectoral inputs

$$
\begin{aligned}
L & =(1-p) L_{1}+p L_{2}, \\
K & =(1-p) K_{1}+p K_{2} .
\end{aligned}
$$
}


Decomposition Formula Equating the two versions of growth accounting identity (32) and (36), we can obtain a formula that decomposes aggregate TFP growth TFPG into four underlying sources:

$$
T F P G=F I N+O C C+C H+W S R
$$

where

$$
\begin{aligned}
F I N & \equiv\left[\widetilde{s}_{Y_{2}} \frac{\Pi_{2}}{Y_{2}}-\widetilde{s}_{Y_{1}} \frac{\Pi_{1}}{Y_{1}}\right] p g_{p}: \text { Financial-deepening effect } \\
O C C & \equiv(1-p) \widetilde{s}_{Y_{1}} O C C_{1}+p \widetilde{s}_{Y_{2}} O C C_{2}: \text { Occupational-shift effect } \\
C H & \equiv s_{U} g_{K_{1}}: \text { Capital-heterogeneity effect } \\
W S R & \equiv(1-p) \widetilde{s}_{Y_{1}} S R_{1}+p \widetilde{s}_{Y_{2}} S R_{2}: \text { Within-sector Solow residuals }
\end{aligned}
$$

and $O C C_{j}$ and $S R_{j}$ denote within-sector occupational-shift effect and within-sector Solow residual of sector $j$ for $j=1,2$, defined as:

$$
\begin{aligned}
S R_{j} & \equiv g_{Y_{j}}-\left(\frac{r K_{j}}{Y_{j}}\right) g_{K_{j}}, \\
O C C_{j} & \equiv-s_{L_{j}} g_{L_{j}} .
\end{aligned}
$$

The financial-deepening effect, $F I N$, captures the contribution of the expansion of the intermediated sector $\left(p g_{p}\right)$ on TFP growth. Equation (38) shows that financial deepening affects TFP through the gap in profitability, measured by profits normalized to output, between credit and non-credit sectors $\left(\widetilde{s}_{Y_{2}} \frac{\Pi_{2}}{Y_{2}}-\widetilde{s}_{Y_{1}} \frac{\Pi_{1}}{Y_{1}}\right)$, not through the sectoral output gap. Given the sectoral output gap $\left(Y_{2}>Y_{1}\right)$, financial deepening will increase aggregate output but not necessarily productivity. Thus, observing the output differential between the two sectors can be misleading in an attempt to understand the effect of financial deepening on productivity growth. Aggregate productivity grows from financial deepening only when normalized profits of the intermediated sector are higher than the non-intermediated sector. The occupational-shift effect, $O C C$, is a weighted sum of occupational shift effects within sectors, $O C C_{1}$ and $O C C_{2}$. Changes in factor prices and profits affect both $O C C_{1}$ and $O C C_{2}$. In the non-credit sector, wealth accumulation also affects $O C C_{1}$. The $C H$ captures the effect of compositional changes in heterogeneous capital between the credit and non-credit sectors.

The $W S R$ is a weighted sum of standard Solow residuals $S R_{1}$ and $S R_{2}$ within sectors. The dual measure of the within-sector Solow residuals, $D W S R$, is defined as a weighted sum of growth rates of factor prices and $\operatorname{profits}^{28}$ :

$$
D W S R \equiv s_{L} g_{w}+p \widetilde{s}_{Y_{2}} s_{K_{2}} g_{r}+(1-p) \widetilde{s}_{Y_{1}} s_{\Pi_{1}} g_{\Pi_{1}}+p \widetilde{s}_{Y_{2}} s_{\Pi_{2}} g_{\Pi_{2}} .
$$

\footnotetext{
${ }^{28}$ Hsieh (2002) applied the dual approach in accounting for growth of other East Asian countries. Here, we explicitly incorporate profits and our dual measure of Solow residuals is the sum of sectoral Solow residuals. Fernanad and Neiman (2003) argue the importance of explicit consideration of profits and heterogeneous costs of capital (though they emphasize the government-directed credit availability) in reconciling the TFP growth estimates of the East Asian countries between Young (1995) and Hsieh (2002).
} 
The primary measure $W S R$ is related to the dual measure $D W S R$ :

$$
W S R=D W S R-C H-O C C .^{29}
$$

This suggests that WSR is determined by (endogenous) movements of factor prices and profits, net of the heterogeneity effects $C H$ and $O C C$.

\section{B Decomposition of Simulated TFP Growth}

We apply the above growth accounting method, which allows us to get inside of the "residual," to both the model and the actual Thai data and quantitatively measure the underlying sources of the total factor productivity growth.

Figure 7 displays aggregate TFP growth from the model and the four sources, FIN, OCC, CH, and WSR, calculated from the equations (38), (39), (40), and (41), respectively. The occupational-shift effect $(O C C)$ is tiny. The capital-heterogeneity effect $(\mathrm{CH})$ is small except during the initial years, when the interest rate in the model is very high (above 60 percent per annum). The within-sector Solow residuals (WSR) seem small also again except in the initial years and in the early 1990's. The dominant source of aggregate TFP growth in the model is the financial-deepening effect $(F I N)$, especially during the second decade of 1986-1996, when the expansion of the credit sector accelerated, as shown in Figure 4.

Allowing occupational choice plays a key role in the model because this selection generates rents to talent, through which financial intermediation affects TFP. However, the size of the direct occupational shift effect on TFP $O C C$ turns out to be small. This is due to the general equilibrium effects on occupational choice, i.e., due to the endogenous movements of factor prices accompanying growth. The wage (Figure 8.1) stays constant at the reservation level until 1990 and then grows steadily and fast. The interest rate (Figure 8.2) continuously declines, a typical feature of diminishing returns to capital accumulation (with the exception of the small rise

\footnotetext{
${ }^{29}$ From the accounting identity for sectoral output growth $g_{Y_{j}}=s_{L_{j}}\left(g_{L_{j}}+g_{w}\right)+s_{K_{j}}\left(g_{K_{j}}+g_{r_{j}}\right)+s_{\Pi_{j}} g_{\Pi_{j}}$, for $j=1,2$.
}

we have

$$
\begin{aligned}
S R_{1} & \equiv g_{Y_{1}}-\left(\frac{r K_{1}}{Y_{1}}\right) g_{K_{1}} \\
& =g_{Y_{1}}-s_{K_{1}} g_{K_{1}}-\frac{(r-1) K_{1}}{Y_{1}} g_{K_{1}} \\
& =s_{L_{1}} g_{w}+s_{\Pi_{1}} g_{\Pi_{1}}+s_{L_{1}} g_{L_{1}}-\frac{s_{U} g_{K_{1}}}{p \widetilde{s}_{Y_{1}}}
\end{aligned}
$$

and

$$
\begin{aligned}
S R_{2} & \equiv g_{Y_{2}}-s_{K_{2}} g_{K_{2}} \\
& =s_{L_{2}} g_{w}+s_{K_{2}} g_{r}+s_{\Pi_{2}} g_{\Pi_{2}}+s_{L_{2}} g_{L_{2}} .
\end{aligned}
$$

Substituting the $S R_{1}$ and $S R_{2}$ as above into $W S R$ in (41), we get

$$
W S R=D W S R-C H-O C C .
$$


in 1986 when the financial expansion starts to accelerate). Profits (Figure 8.3) of the credit sector respond to these factor price movements; first increasing when the interest rate declines fast and the wage is constant (1976-1982), stable when the interest rate is stabilized and the wage is still constant (1982-1990), then declining when the interest rate declines but the wage increases fast (1990-1996). Figure 8.4 shows the population fraction of entrepreneurs in the credit sector follows a similar pattern, responding to this movement of profits.

In the non-credit sector, profits respond only to the wage, not to the interest rate. Profits (Figure 8.3) of the non-credit sector are only slightly increasing over time, even when the wage grows after 1990. Wage growth has two effects in the non-credit sector. First, it directly decreases the profits of the incumbent entrepreneurs, but second, it helps wealth accumulation and hence facilitates the occupational shifts of poor but talented people from wageworkers to entrepreneurs. The latter effect is larger than the first one, but the population fraction of entrepreneurs in the non-credit sector increases only slightly, i.e., $-g_{L_{1}}$ is close to zero in (39). Figure 8.5 shows that the sectoral wage share of the non-credit sector, $(1-p) \widetilde{s}_{Y_{1}} s_{L_{1}}$, is much larger than that of the credit sector, $p \widetilde{s}_{Y_{2}} s_{L_{2}}$, in (39). That is, $O C C$ is dominated by $O C C_{1}$ which is small, and hence so is $O C C$.

Figure 8.6 shows that the profitability gap, $\left(\widetilde{s}_{Y_{2}} \frac{\Pi_{2}}{Y_{2}}-\widetilde{s}_{Y_{1}} \frac{\Pi_{1}}{Y_{1}}\right)$ in (38), decreases over time, slowly until 1986, and much more rapidly after the accelerated expansion of the credit sector. Note that the start of the sharp decline in the profitability gap is associated with the financial expansion, not with wage growth, though wage growth reinforces the convergence in profitability between the two sectors. With this decrease in the profitability gap, the financial-deepening effect gradually gets smaller (see Figure 7) despite the continual expansion of the credit sector after 1986 (see Figure 4).

The sectoral Solow residuals $S R_{1}$ and $S R_{2}$ show different responses to wage growth, as shown in Figure 9. After the wage starts to grow, $S R_{1}$ surges from zero to $2.5 \%$ but $S R_{2}$ drops from zero to $-2 \%$. This is related to the contrasting response of profits between sectors to the wage growth. In the non-credit sector (sector 1), wage growth helps wealth accumulation and hence the occupational shifts of poor but talented people from wageworkers to entrepreneurs. New entrants to enterprise are more efficient than the incumbents, which reduces the average fixed cost and tends to increase profits. There are no such positive effects of wage growth in the credit sector (sector 2), because within-sector occupational choices are already efficient. Wage growth simply reduces profits in the credit sector.

This suggests an interesting lesson for future study of TFP at disaggregated subgroup levels. Within each subgroup, there are still two types of agents, those who have access to credit and those who don't. The degree of limited access to credit may well vary across subgroups. The different magnitudes of the measured Solow residuals across subgroups may simply reflect these differential degrees of limited access to credit, rather than differences in technical changes across subgroups. Suppose, for example, manufacturing is more intermediated than agriculture. Then, the Solow residual of the less intermediated sector, agriculture, may be larger than 
that of the more intermediated sector, manufacturing when wage increases. ${ }^{30}$ Furthermore, the possibility of counteracting movements of sectoral Solow residuals suggests that the sum of the measured sectoral Solow residuals may appear small although each sector experiences substantial changes in TFP. This suggests that explicit consideration of the varying degrees of intermediation is crucial to the TFP study at both aggregate and disaggregate levels.

\section{Decomposition of Actual Thai TFP Growth}

\section{C.1 Measurement}

Now we measure and decompose actual Thai TFP growth using the same decomposition method. The difficulty in doing this is that key variables such as shares and quantities of capital and labor and profits need to be differentiated according to having access to credit or not. Use of micro data helps to resolve this problem.

Thai aggregate Solow residual $S R^{T h a i}$ is obtained from the standard growth accounting, as was already calculated (displayed in Figure 1). We filter out the effects of growth from the increase in the quantity and quality of labor, as well as from the expansion of cultivated land that are not in the model. We can then compare TFP in the Thai data to TFP as in the model. To construct TFPG for Thailand, we need to take two kinds of heterogeneity into account, labor-heterogeneity effect $\left(-s_{L} g_{L}\right)$ and capital-heterogeneity effect $\left(s_{U} g_{U}\right)$ such that $T F P G=S R-s_{L} g_{L}+s_{U} g_{U}$.

The growth rate of the fraction of entrepreneurs $\left(-g_{L}\right)$ is obtained from the occupational choice data in the SES and the income share of non-entrepreneurs $\left(s_{L}=\frac{w L}{Y}\right)$ from the income data again in the SES. Thus, we get the labor heterogeneity effect for Thailand, denoted by $-s_{L} g_{L}^{T h a i}$.

To compute the capital-heterogeneity effect $s_{U} g_{U}$, we would need data for $K_{1}$, the non-intermediated capital. This information is, unfortunately, not available from a typical household survey, and so we cannot isolate this effect. ${ }^{31}$ The capital-heterogeneity effect is thus included in the measured residual $S R^{T h a i}$. Thus, we use

$$
T F P G^{T h a i}=S R^{T h a i}-s_{L} g_{L}^{T h a i}
$$

as our measure of Thai TFP growth.

To measure the financial-deepening effect and occupational-shift effect for Thailand, denoted by FIN ${ }^{T h a i}$ and $O C C^{T h a i}$, respectively, the economy needs to be partitioned into non-credit and credit sectors. As was

\footnotetext{
${ }^{30}$ Tinakorn and Sussangkarn (1998) find it puzzling that the Solow residual of agriculture is larger than the Solow residual of manufacture (which is in fact negative) in Thailand. There have been no significant technological innovations in the Thai agriculture in particular in the rice farming. It is rather manufacturing that has been more open to the possibility of technological innovation through the foreign direct investment for the latter decade. However, if agriculture is less intermediated than manufacturing in Thailand, we may observe higher Solow residual in agriculture than in manufacturing for the period of wage growth.

${ }^{31}$ Non-intermediated capital stock $K_{1}$ and its factor share are available neither from national income data nor from typical household surveys. We may need firm surveys to fetch these pieces of information. For a more comprehensive decomposition, a synthesis between two types of micro data, i.e., firm surveys and household surveys seems needed.
} 
mentioned earlier, the SES records all financial transactions (both borrowing and lending) of each household with all formal financial institutions, and so we can create an indicator variable for the use of any of the formal financial institutions of each household. This allows us to partition the economy into the two sectors. The SES records the wages and profits data for each individual separately. Combining the indicator variable of the financial sector partition with these disaggregated income data, we construct factor shares and profits not only for the aggregate economy, but also for each of the credit and non-credit sectors. That is, we have the necessary information $\Pi_{1}, \Pi_{2}, Y_{1}, Y_{2}, Y$, and $p$ to calculate $F I N^{T h a i}$ as in the equation (38), and $w, L_{1}, L_{2}, Y_{1}, Y_{2}, Y$, and $p$ to calculate $O C C^{T h a i}$ as in equation (39).

\section{C.2 Decomposition Results}

The labor-heterogeneity effect $-s_{L} g_{L}^{T h a i}$ turns out to be small in the Thai data and thus from (46) the aggregate TFP growth TFPG ${ }^{T h a i}$ is very close to the aggregate Solow residual $S R^{T h a i}$ obtained from the standard growth accounting exercise, as shown in Figure 10. On average, $S R^{\text {Thai }}$ is 2.34 percent per year while $T F P G^{T h a i}$ is 2.42 percent.

The components of TFPG $G^{T h a i}$ are displayed in Figure 11. The occupational-shift effect $O C C^{T h a i}$ is small (0.08 percent per year on average) as in the model. The financial-deepening effect FIN ${ }^{\text {Thai }}$ is large (1.69 percent per year on average), also as in the model. These two sources of productivity growth explain 1.77 percent out of the total 2.42 percent of the aggregate TFP growth per year in Thailand during 1976-1996. That is, 73 percent of the Thai TFP growth can be explained by the enhanced allocation efficiency (3 percent from within-sector occupational shift plus 70 percent from financial deepening). In other words, explicit consideration of occupational choice and financial deepening eliminates about three-quarter of the "measure of our ignorance" of the growth process.

We cannot isolate the capital-heterogeneity effect $C H$ for Thailand, due to lack of data on the capital stock differentiated by access to credit. However, we can calculate a dual measure of within-sector Solow residual, $D W S R$, using price data as in equation (44). Rewriting (44),

$$
D W S R=s_{L} g_{w}+\frac{p r K_{2}}{Y} g_{r}+\frac{(1-p) \Pi_{1}}{Y} g_{\Pi_{1}}+\frac{p \Pi_{2}}{Y} g_{\Pi_{2}} .
$$

Replacing $\frac{K_{2}}{Y}$ by $\frac{K}{Y}$, we approximate $D W S R$ for Thailand by

$$
D W S R^{T h a i} \approx s_{L} g_{w}+\frac{p r K}{Y} g_{r}+\frac{(1-p) \Pi_{1}}{Y} g_{\Pi_{1}}+\frac{p \Pi_{2}}{Y} g_{\Pi_{2}} \cdot{ }^{32}
$$

In Figure 11, we see a big hump for $D W S R^{T h a i}$ during the second decade of wage growth period, peaking at 7\% in 1990 and then declining to zero in 1994. That is, the combined effect of movements of factor prices and

\footnotetext{
${ }^{32}$ Here, we bear a measurement error coming from the difference in capital-output ratios between aggregate economy and credit sector. When the capital share of credit sector is higher than that of aggregate economy, our measure $D W S R^{T h a i}$ is likely to underestimate the true value.
} 
profits generates non-monotonic TFP dynamics.

From equations (37) and (45), the aggregate TFP growth of the model can be rewritten

$$
T F P G=F I N+D W S R .
$$

If the model were a precise description of the Thai economy, TFPG $G^{T h a i}$ would be explained by $F I N^{T h a i}$ and $D W S R^{T h a i}$. Defining a residual term

$$
R E S^{T h a i}=T F P G^{T h a i}-F I N^{T h a i}-D W S R^{T h a i},
$$

the $R E S^{T h a i}$ measures a remainder TFP growth in Thailand that is not explained by the model. This may include productivity changes from policy reforms or distortions (not related to financial deepening and occupational shifts), or changes in pure technical efficiency. Although the average size of $R E S^{T h a i}$ is small at $-0.9 \%$, $R E S^{T h a i}$ does closely track big movements of TFPG $G^{\text {Thai }}$ during 1976-1981 and 1987-1996 periods. In particular, it plummeted to -9\% in 1990 and stays negative till 1996. Thailand after the mid-1980's seemed to have big negative productivity shocks (either from policy distortions or to technical regress) while the allocation efficiency improved through financial deepening and occupational shifts for the same period. This perhaps presages the upcoming crisis in 1997.

The key variables underlying the Thai TFP growth, $T F P G^{T h a i}$, are displayed in Figure 12. (The analogue of the model was Figure 8.) The Thai wage (Figure 12.1) shows the take-off dynamics, staying constant until 1986 with a sudden and continued growth thereafter. The Thai real interest rate (Figure 12.2), measured by the prime lending rates of the four largest Thai commercial banks, does not show a monotonic trend. Rather it surges during 1980-1984, with a sharp decrease during 1985-1989, then stable thereafter.

Figure 12.3 displays the profits levels of the non-credit and credit sectors. Before 1981, profits were stable (only slightly increasing in the credit sector and slightly decreasing in the non-credit sector). During the recession period, 1981-1986, profits declined in both sectors. After the wage started to grow, movements of profits differ between the two sectors. Profits increased continually with the wage growth in the non-credit sector, consistent with the model. But profits increased in the credit sector as well during 1988-1992, despite the wage growth. In sum, the movement of profits of the Thai credit sector is different from the prediction of the model. This anomaly appears in the fraction of entrepreneurs as well, which increased in both sectors when the wage grew, as shown in Figure 12.4. This suggests that the credit sector of the actual Thai economy is not as perfect as is assumed in the model.

As shown in Figure 12.5, Thai wage share is larger in the non-credit sector than in the credit sector and that the gap becomes smaller, both as in the model. Thus, the occupational-shift effect is mainly governed by occupational shift in the non-credit sector, the magnitude of which is small (see Figure 12.4). This explains the 
small size of $O C C^{\text {Thai }}$. The profitability gap between the two sectors (Figure 12.6) slightly increased until 1986, suddenly dropped for two years when the wage started to grow, bounced back during 1988-1992, and declined fast thereafter. Thus follows the decline of FIN Thai for this latter period, as observed in Figure 11, despite the continual expansion of the credit sector.

\section{Model Evaluation}

We already observed in Figure 6 that the model predicts the aggregate dynamics well. In part, from output growth and labor share, it is calibrated to do so. However, neither aggregate TFP growth nor its components, which we want to explain, were used in calibration. Figure 13 shows that the model predicts the main components of TFP growth, financial-deepening and occupational-shift effects well. In particular, the financial-deepening effect on TFP growth from the model remarkably resembles the actual Thai data, in terms of both movement and magnitude. The occupational-shift effect is small in both the model and the data due largely to the stability of the fraction of entrepreneurs within each sector, due again to the general equilibrium movements of factor prices that counteract each other for the occupational choice.

We performed sensitivity analysis. The Figures A.1 to A.7 show some representative results of the sensitivity analysis. The simulated dynamics of output and TFP growth and the sources of TFP growth turn out to be robust to the perturbation of parameters. In particular, changes in the capital coefficients $\alpha$, $\beta$, and $\sigma$ make virtually no difference. Changing the labor coefficients of $\xi$ and $\rho$, savings propensity $\omega$, and subsistent income $\gamma$ seem to give more variation to the dynamics of output and TFP. However, the orders of magnitude of changes

from varying these parameters are still small. In particular, the size and the movements of the financial-deepening effect on the TFP growth remain robust to every perturbation.

There are several noticeable features in the data which the model cannot explain. First, the fraction of subsisters should completely vanish once the wage starts to grow. Better identifying who are the traditional subsisters in the data is a separate empirical issue. However, whoever they are, the model cannot accommodate the coexistence of modern entrepreneurs and traditional subsisters together with wage growth. At least some Thai farmers, in particular the small-scale rice farmers, are likely to use traditional technology, yet they do not vanish with the strong wage growth in Thailand, as shown in Figure 14.1. This failure seems to come from the simplification of the fixed return to labor in the traditional sector. Second, the model predicts that the fraction of entrepreneurs should decrease in the credit sector as wage grows, but the fraction of entrepreneurs increases during the 1988-1996 period when wage grows in the data, as shown in Figure 14.2. This suggests that the intermediation within the credit sector seems less than perfect in the data, unlike the presumption of the model. Third, the big negative productivity shocks after the mid-1980's, as picked up in $R E S^{T h a i}$, are not captured by 
the model.

These anomalies may guide the search for an even better theory of TFP. For example, Jeong and Kim (2006) show that sector-specific complementarity between work experience and labor is helpful in generating a smooth and gradual S-shaped transition, correcting the first failure and providing another channel of TFP. The role of imperfect intermediation within credit sector has yet to be studied.

\section{Conclusion}

Existing TFP literature usually measures the size of TFP but rarely directly identifies its underlying sources. The sources of TFP growth typically remain unknown inside the residual. We attempted to find what is inside of the residual using both data and models. We combined micro data with macro data and developed a method of TFP growth accounting based on a growth model with occupational choice under limited access to credit. TFP growth was decomposed into four components; financial-deepening, occupational-shift, capitalheterogeneity, and within-sector Solow residuals. Applied to Thailand, we found that explicit consideration of occupational choice and financial deepening eliminates about three-quarters of the "measure of our ignorance" of the growth process. In particular, we found direct evidence for the finance-growth nexus through this TFP growth accounting exercise.

The interactive evolution between factor prices and wealth distribution matters for TFP dynamics, and depends on access to credit. Several implications follow for growth accounting. First, an aggregate production function without incorporating the wealth distribution may fail to capture important growth dynamics. Second, differential profitability and heterogeneous costs of capital play an important role understanding TFP. Third, varying degrees of limited access to credit across sub-groups of the economy can be a source of differences in TFP at a disaggregated level. Finally, take-off wage dynamics, a typical feature of dual economy models, can be generated as an equilibrium phenomenon.

Occupational choice and credit constraints have long been considered important dimensions in understanding the development process. The development literature has searched and found ample micro evidence for the importance of both. We brought a growth model with micro underpinnings that incorporates occupational choice and credit constraints to macroeconomics, and confirmed its quantitative importance in explaining aggregate TFP.

\section{References}

[1] Abramovitz, Moses (1956), "Resource and Output Trends in the United States since 1870," American Economic Review, V. 46: 5-23. 
[2] Alba, Pedro, Leonardo Hernandez, and Daniela Klingebiel (1999), "Financial Liberalization and the Capital Account: Thailand, 1988-97," Policy Research Working Paper No. 2188, World Bank.

[3] Amral, Pedro, and Erwan Quintin (2005), "Financial Intermediation and Economic Development: A Quantitative Assessment," mimeo.

[4] Banerjee, Abhijit, and Esther Duflo (2005), "Growth Theory Through the Lens of Development Economics," Ch. 7 in Handbook of Economic Growth, ed. by P. Aghion and S. Durlauf, Vol. 1A. Amserdam: Elsevier.

[5] Banerjee, Abhijit, and Andrew Newman (1993), "Occupational Choice and Process of Development," Journal of Political Economy V. 98: 274-298.

[6] Beck, Thorsten, Asli Demirgüç-Kunt, and Vojislav Maksimovic (2002), "Financial and Legal Constraints to Firm Growth," World Bank Policy Research Working Paper No. 2784.

[7] Beck, Thorsten, Ross Levine, and Norman Loayza (2000), "Finance and the Sources of Growth," Journal of Financial Economics, V. 58: 261-300.

[8] Bencivenga, Valerie R., and Bruce Smith (1991), "Financial Intermediation and Endogenous Growth," Review of Economic Studies, V. 58: 195-209.

[9] Bergoeing, Raphael, Patrick J. Kehoe, Timothy J. Kehoe, and Raimundo Soto (2002), "Decades Lost and Found: Mexico and Chile Since 1980," Review of Economic Dynamics, V. 5: 166-205.

[10] Caselli, Francesco and Nicola Gennaioli (2005), "Dynastic Management," mimeo.

[11] Caselli, Francesco (2005), "Accounting for Cross-Country Income Differences," Ch. 9 in Handbook of Economic Growth, ed. by P. Aghion and S. Durlauf, Vol. 1A. Amserdam: Elsevier.

[12] Denison, Edward F. (1969), "Some Major Issues in Productivity Analysis: An Examination of Estimates by Jorgenson and Griliches," Survey of Current Business, V. 49: 1-27.

[13] Erosa, Andrés, and Hidalgo Cabrillana (2005), "On Capital Market Imperfections as a Source of Low TFP and Economic Rents," mimeo.

[14] Fernald, John, and Brent Neiman (2003), "Measuring Productivity Growth in Asia: Do Market Imperfections Matter?" mimeo.

[15] Fuss, Melvyn, Daniel McFadden, and Yair Mundlak (1978), "A Survey of Functional Forms in the Economic Analysis of Production," in Melvyn Fuss and Daniel McFadden eds., Production Economics: A Dual Approach to Theory and Application, Amsterdam, North-Holland, Vol. 1: 219-268. 
[16] Goldsmith, Raymond W. (1969), Financial Structure and Development, New Haven: Yale University Press.

[17] Gollin, Douglas (2002), "Getting Income Shares Right," Journal of Political Economy, V. 110 (2): 458474.

[18] Gollin, Douglas, Stephen L. Parente, and Richard Rogerson (2002), "Structural Transformation and Cross-Country Income Differences," mimeo.

[19] Greenwood, Jeremy and Jovanovic, Boyan (1990), "Financial Development, Growth, and the Distribution of Income," Journal of Political Economy, V. 98: 1076-1107.

[20] Hansen, Gary, and Edward C. Prescott (2002), "Malthus to Solow," American Economic Review, V. 92: 1205-1217.

[21] Hicks, John (1965), Capital and Growth, Oxford University Press, Oxford.

[22] Hsieh, Chang-Tai (2002), "What Explains the Industrial Revolution in East Asia? Evidence from the Factor Markets," American Economic Review, V. 92: 502-526.

[23] Jeong, Hyeok (2000), Sources of Kuznets Dynamics in Thailand, Ph.D. Dissertation, University of Chicago.

[24] Jeong, Hyeok (2006), "Assessment of Relationship Between Growth and Inequality: Micro Evidence from Thailand," Macoeconomics Dynamics, forthcoming.

[25] Jeong, Hyeok and Yong Kim (2006), "Complementarity and Transition to Modern Economic Growth," Institute for Economic Policy Research Working Paper Series No. 06.44.

[26] Jeong, Hyeok, and Robert M. Townsend (2006), "Growth and Inequality: Model Evaluation Based on an Estimation-Calibration Strategy," Macoeconomics Dynamics, forthcoming.

[27] Jones, Charles I. (2003), "Growth, Capital Shares, and a New Perspective on Production Functions," mimeo.

[28] Jorgenson, Dale W., and Zvi Griliches (1967), "The Explanation of Productivity Change," Review of Economic Studies, V. 34: 349-83.

[29] Jorgenson, Dale W., and Zvi Griliches (1972), "Issues in Growth Accounting: A Reply to Edward F. Denison, and Final Reply," Survey of Current Business, V. 52: 31-111, (Special Issue, The Measurement of Productivity). 
[30] Kehoe, Timothy J., and Edward C. Prescott (2002), "Great Depressions of the Twentieth Century," Review of Economic Dynamics, V. 5: 1-18.

[31] King, Robert G., and Ross Levine (1993), "Finance and Growth: Schumpeter Might Be Right," Quarterly Journal of Economics, V. 108: 717-737.

[32] Klenow, Peter J., and Andrés Rodríguez-Clare (1997), "The Neoclassical Revival in Growth Economics: Has It Gone Too Far?," NBER Macroeconomics Annual, 73-102.

[33] Kuznets, Simon (1966), Modern Economic Growth, New Haven: Yale University Press.

[34] Levine, Ross, and Sara Zervos (1998), "Stock Markets, Banks, and Economic Growth," American Economic Review, V. 88: 537-558.

[35] Lewis, William A. (1954), "Economic Development with Unlimited Supplies of Labor," Manchester School of Economics and Social Studies, V. 22: 139-191.

[36] Lloyd-Ellis, Huw. and Dan Bernhardt (2000), "Enterprise, Inequality, and Economic Development," Review of Economic Studies, V. 67: 147-168.

[37] Lucas, Robert E., Jr. (1978), "On the Size Distribution of Business Firms," Bell Journal of Economics, V. $9(2): 508-523$.

[38] Lucas, Robert E., Jr. (2004), "Life Earnings and Rural-Urban Migration," Journal of Political Economy, V. 112: S29-S59.

[39] McKinnon, Ronald I. (1973), Money and Capital in Economic Development, Washington D.C.: Brookings Institution.

[40] Okuda, Hidenobu and Fumihara Mieno (1999), "What Happened to Thai commercial Banks in the Pre-Asian Crisis Period: Microeconomic Analysis of Thai Banking Industry," Hitotsubashi Journal of Economics, V. 40: 97-121.

[41] Prescott, Edward C. (1998), "Needed: A Theory of Total Factor Productivity," International Economic Review, V.39: 525-552.

[42] Rajan, Rahuuram, and Luigi Zingales (1998), "Financial Dependence and Growth," American Economic Review, V. 88: 559-586.

[43] Ranis, Gustav, and John Fei (1961), "A Theory of Economic Development," American Economic Review, V. 51: 533-565. 
[44] Schultz, Theodore W. (1990), Restoring Economic Equilibrium, Cambridge: Basil Blackwell.

[45] Schumpeter, Joseph A. (1911), Theorie der Wirtschaftlichen Entwicklung [The Theory of Economic Development], Leipzig: Dunker \& Humbolt, English Translation in 1934 by Harvard University Press.

[46] Solow, Robert M. (1957), "Technical Change and the Aggregate Production Function," Review of Economics and Statistics, V. 39: 312-320.

[47] Tinakorn, Pranee, and Chalongphob Sussangkarn $(1994,1998)$, "Productivity Growth in Thailand," Thailand Development Research Institute.

[48] Townsend, Robert M. (1978), "Intermediation with Costly Bilateral Exchange," Review of Economic Studies, V. 45: 417-425.

[49] Townsend, Robert M. (1983), "Financial Structure and Economic Activity," American Economic Review, V. 73: 895-911.

[50] Townsend, Robert M., and Kenichi Ueda (2006), "Financial Deepening, Inequality, and Growth: A Model-based Quantitative Evaluation," Review of Economic Studies, forthcoming.

[51] Young, Alwyn (1995), "The Tyranny of Numbers: Confronting the Statistical Realities of East Asian Growth Experience," Quarterly Journal of Economics, V. 110: 641-680. 


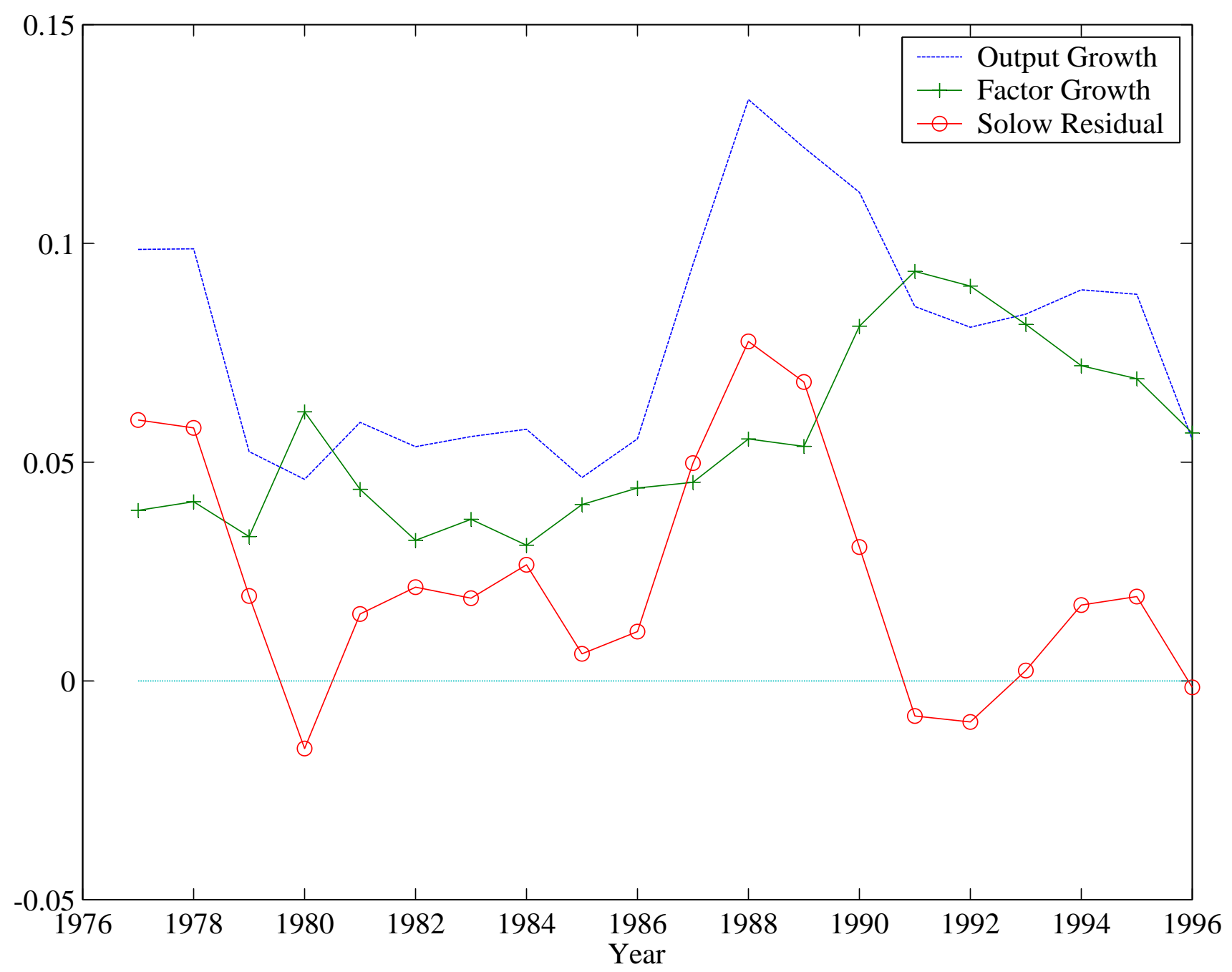

Figure 1. Standard Growth Accounting in Thailand 

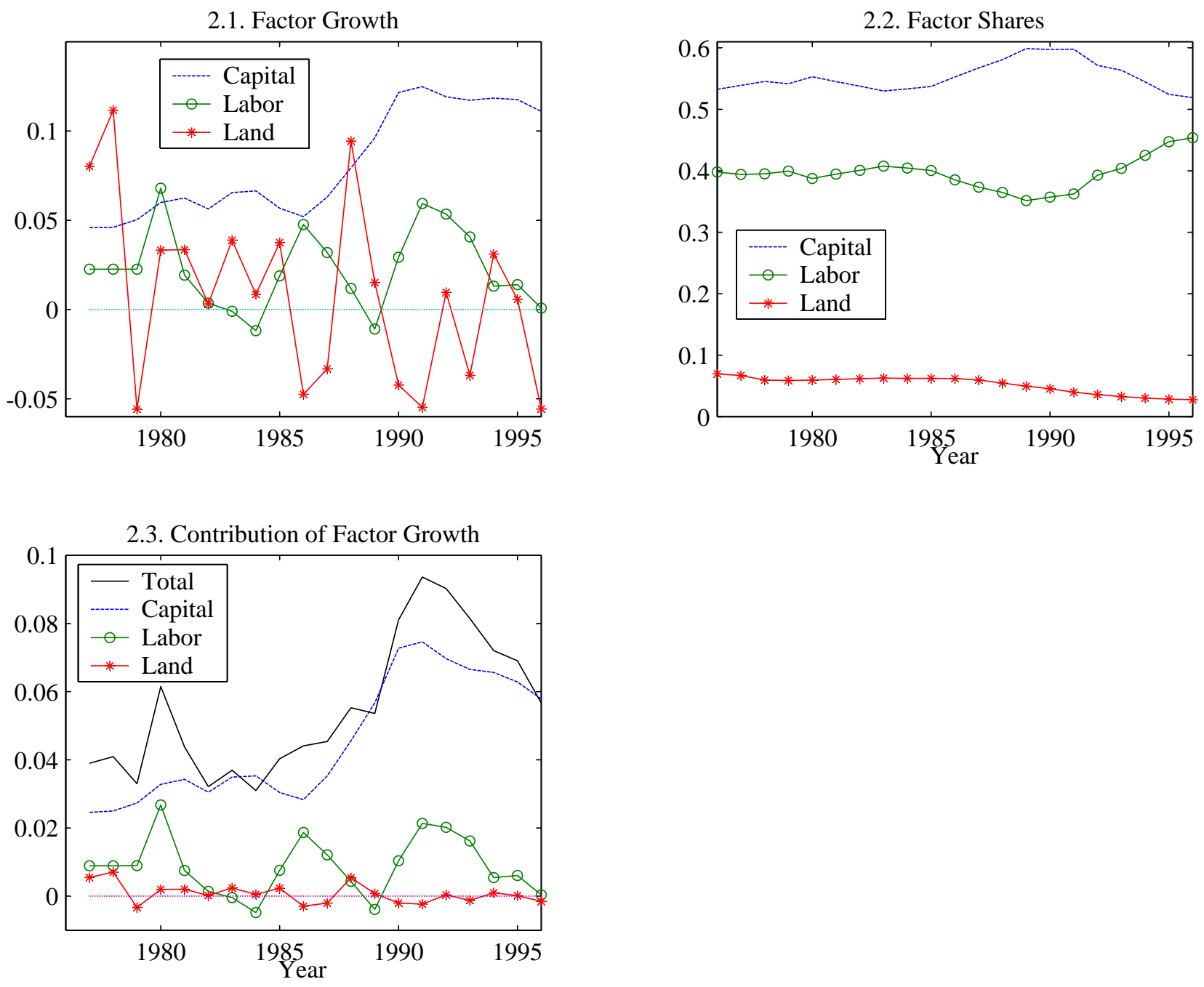

Figure 2. Decomposition of Factor Growth in Thailand 


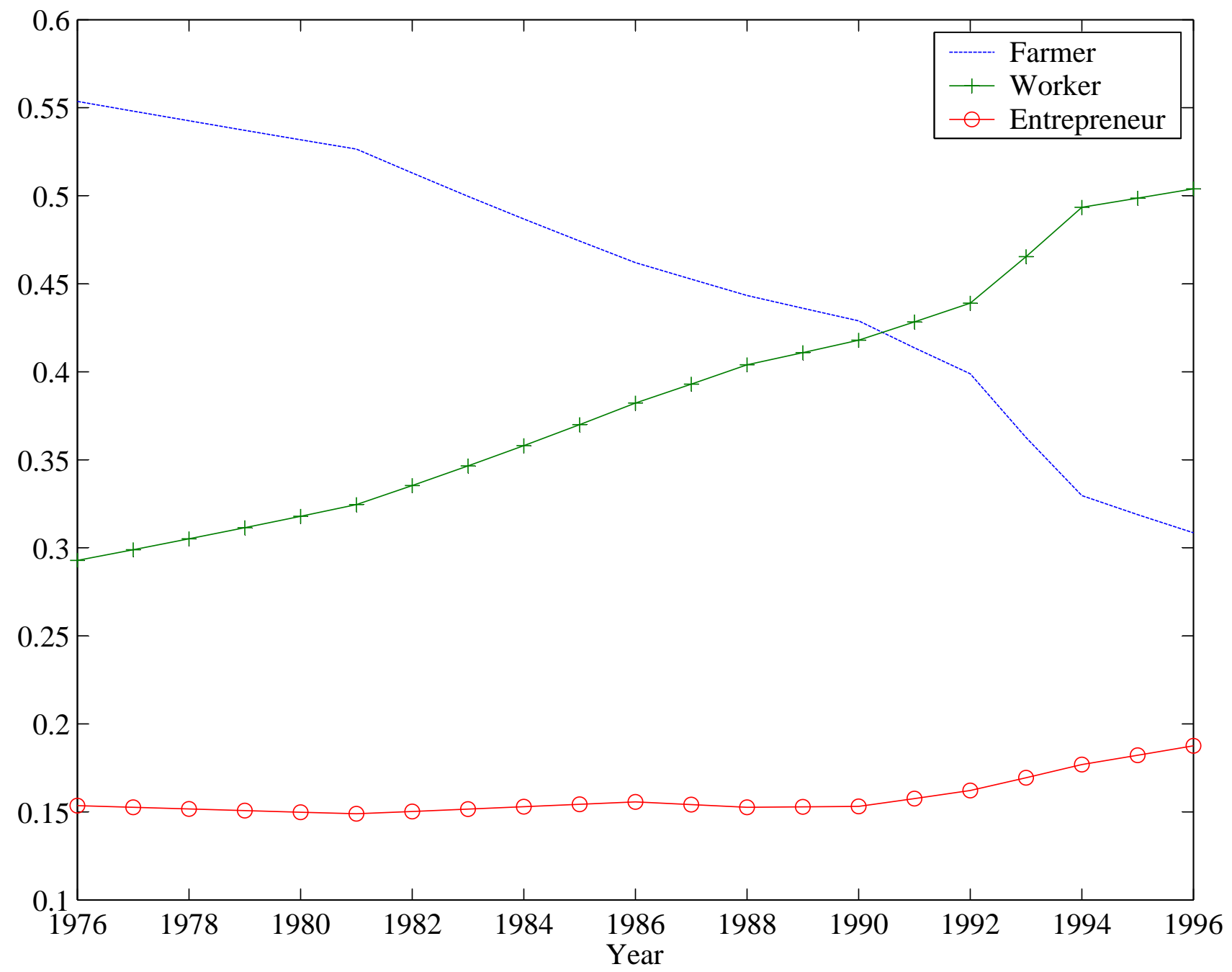

Figure 3. Occupational Transition in Thailand 


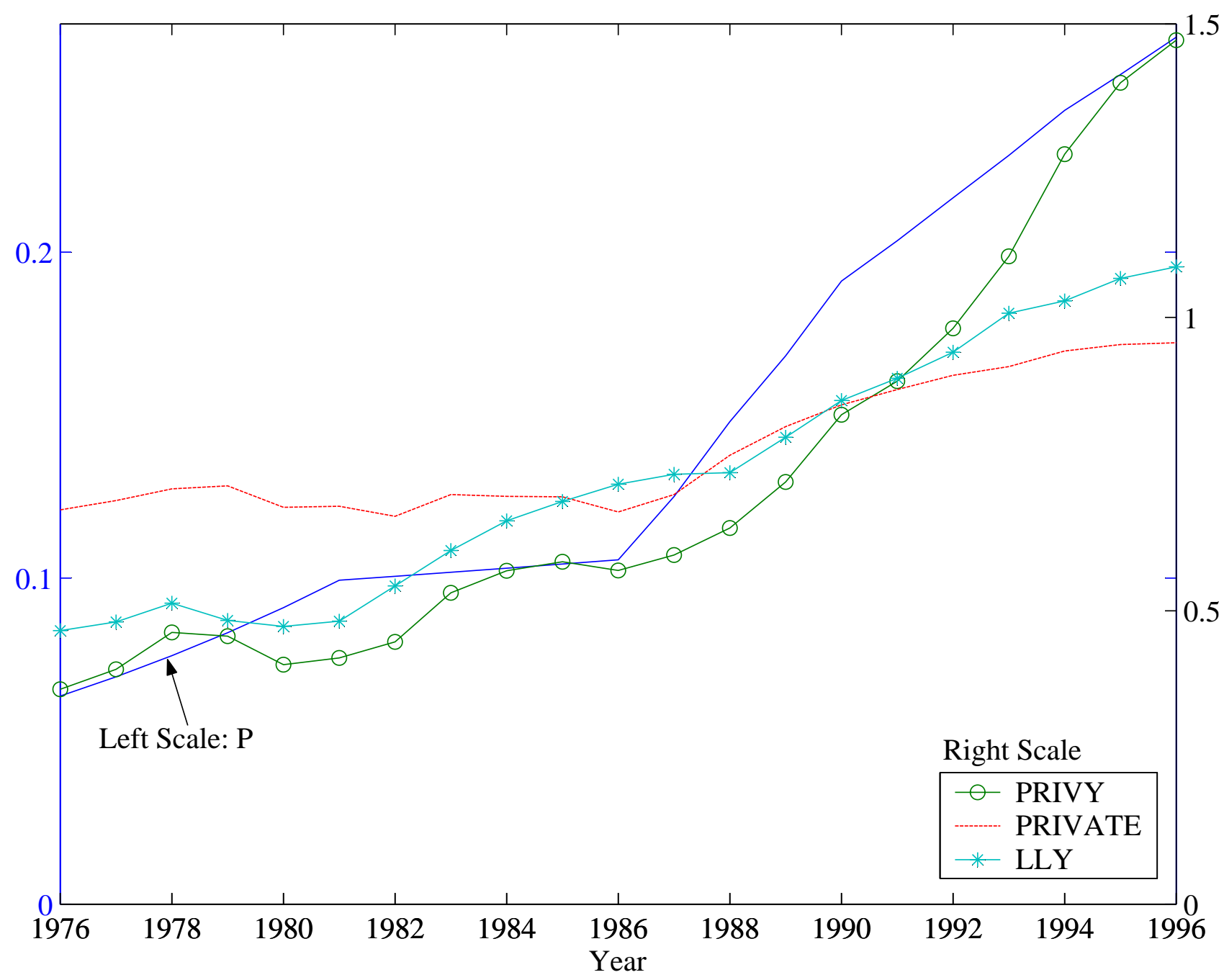

Figure 4. Financial Development in Thailand

Notes: P: Population fraction of formal financial sector from SES. PRIVY: Ratio of private credit to GDP

PRIVATE: Ratio of private credit to total domestic credit. LLY: Ratio of M3 (measure of liquid liabilities) to GDP 

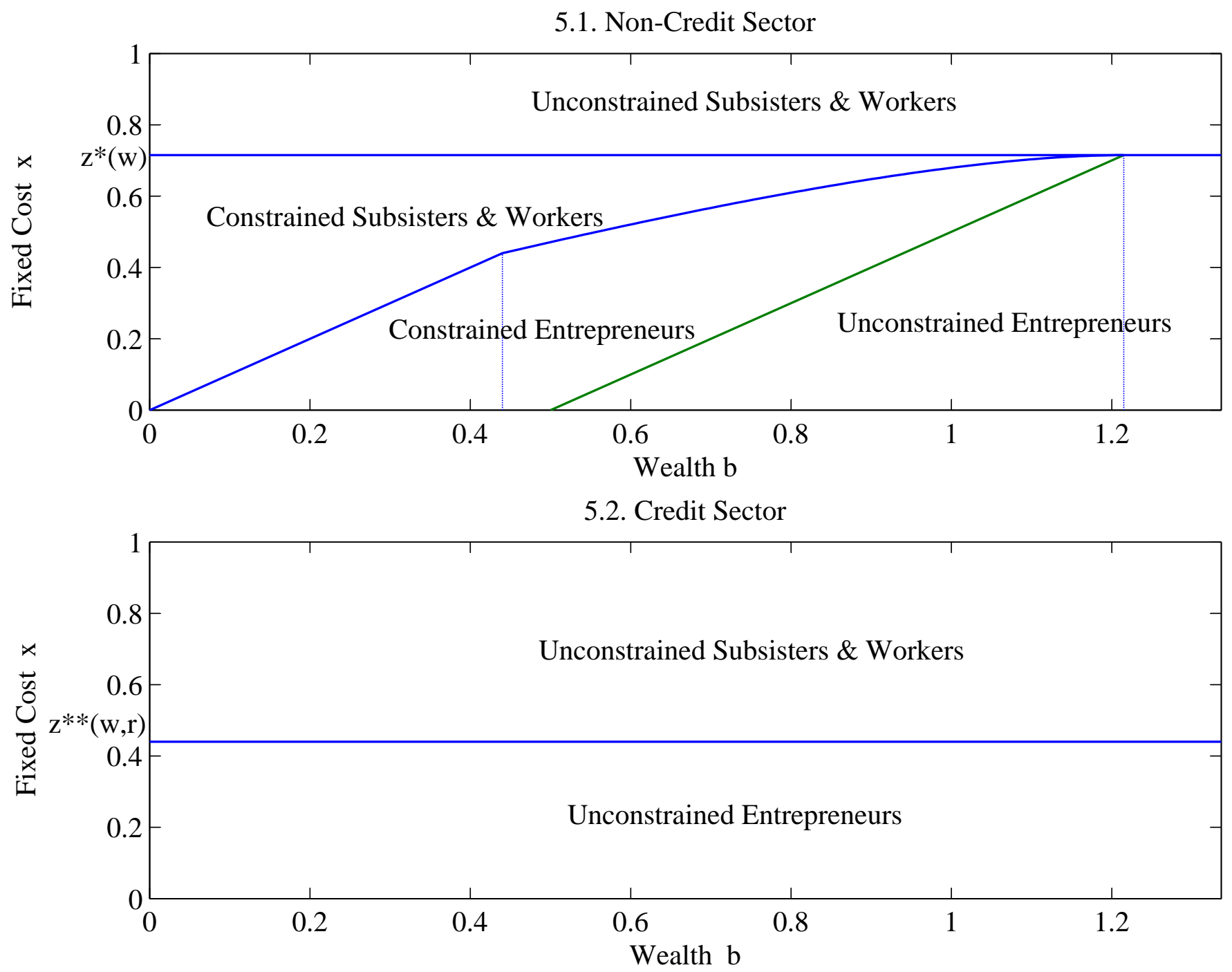

Figure 5. Occupational Choice Maps 
6.1. Output Growth
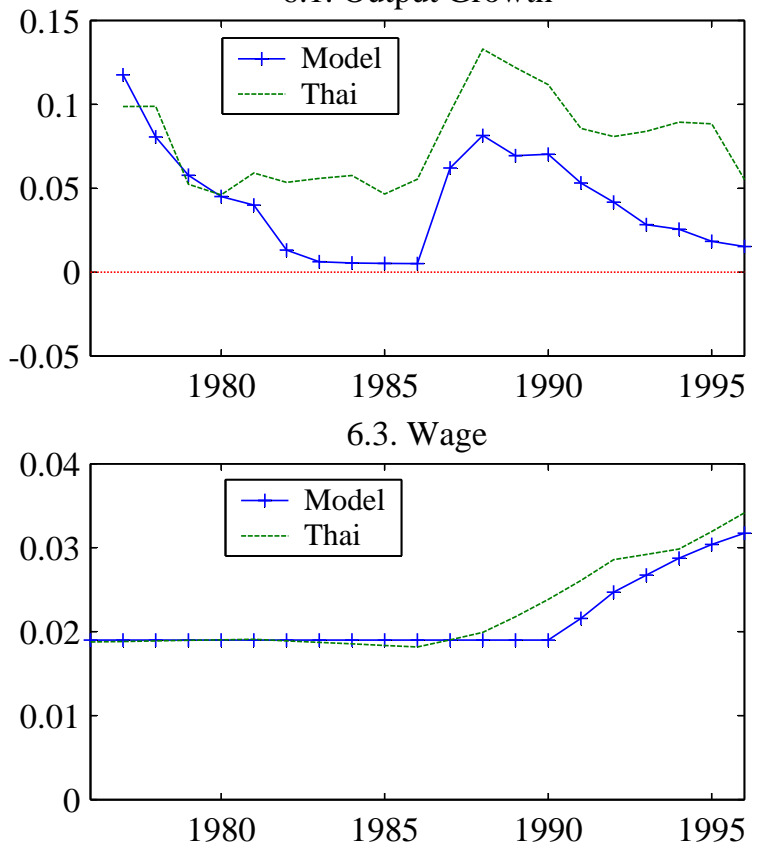

6.5. TFP Growth

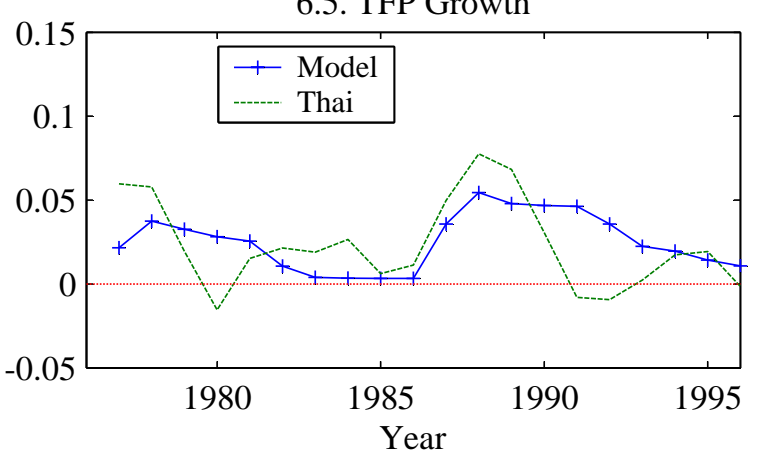

6.2. Labor Share

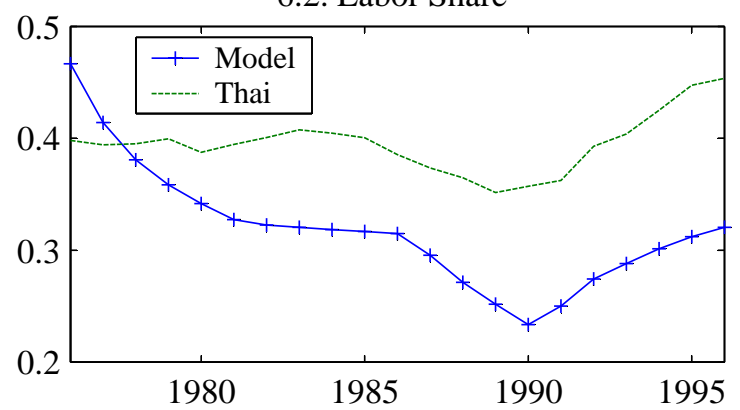

6.4. Fraction of Entrepreneurs

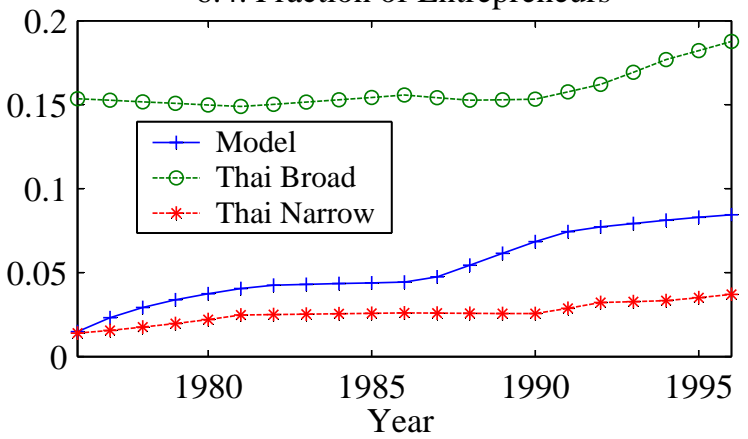

Figure 6. Aggregate Dynamics 


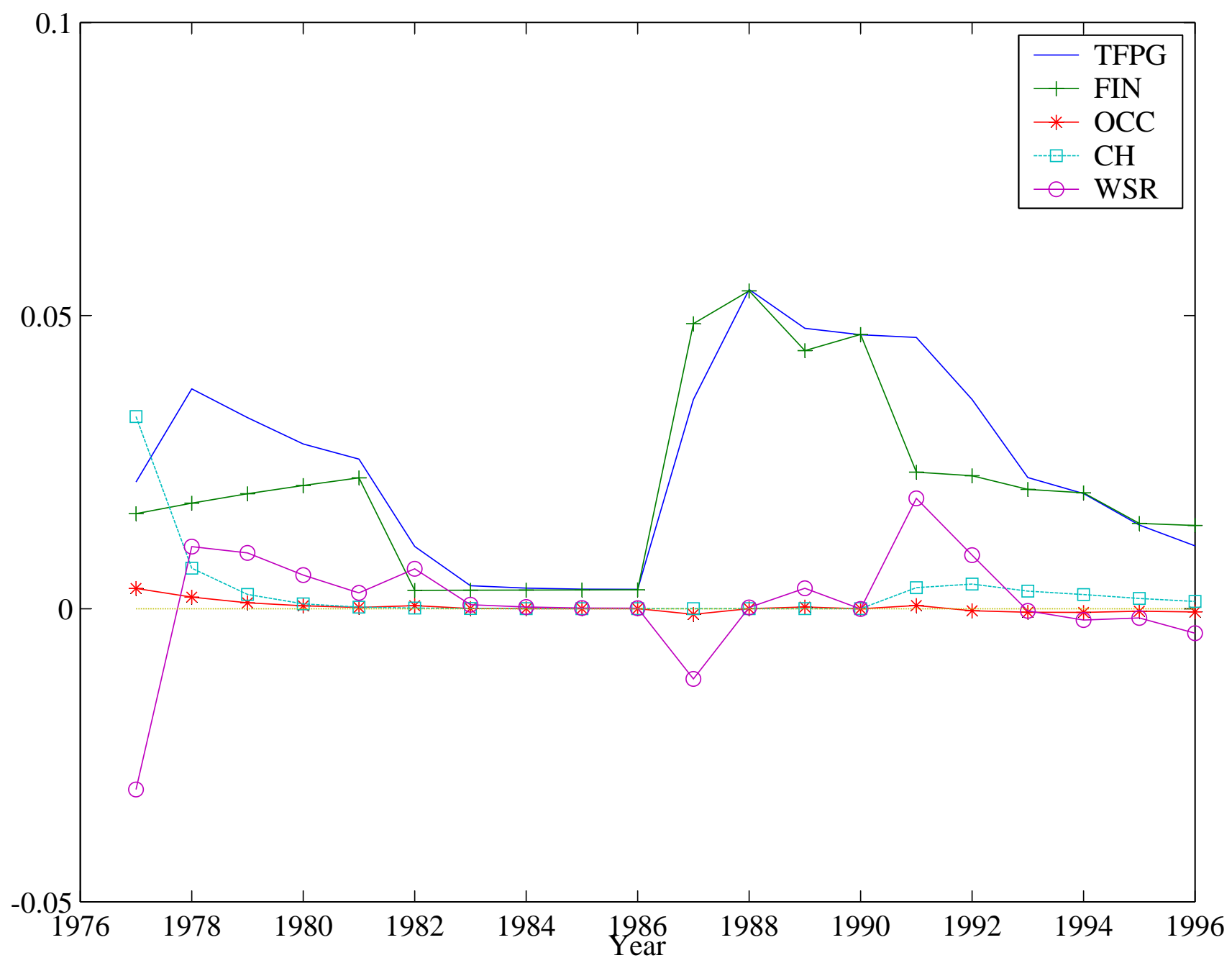

Figure 7. Decomposition of Simulated TFP Growth

Notes: TFPG: TFP Growth in equation (27). FIN: Financial-deepening effect in equation (38). OCC: Occupational-shift effect in equation (39) CH: Capital-heterogeneity effect in equation (40). WSR: Within-sector Solow residual in equation (41). 
8.1. Wage (w)

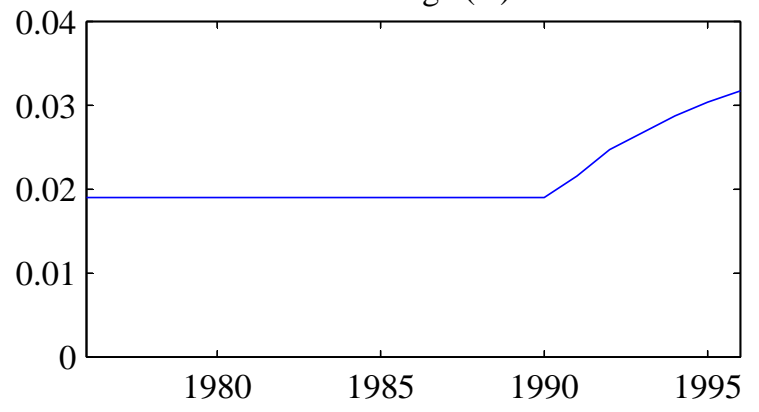

8.3. Profit

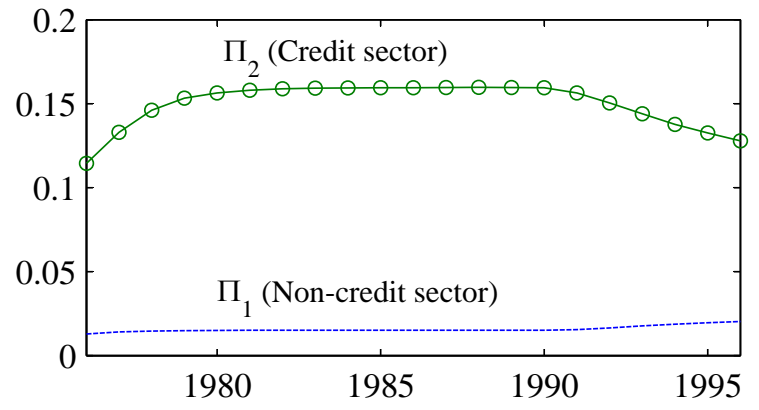

8.5. Sectoral Wage Share

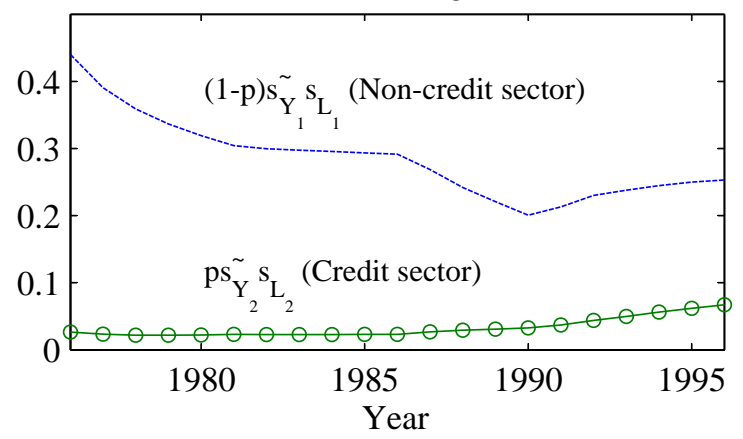

8.2. Interest Rate (r)

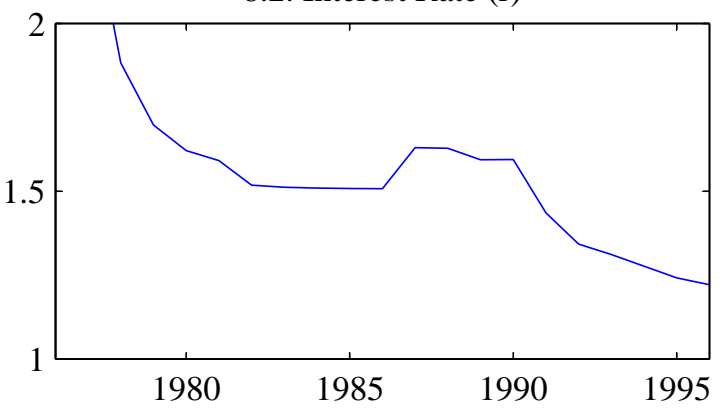

8.4. Sectoral Fraction of Entrepreneurs

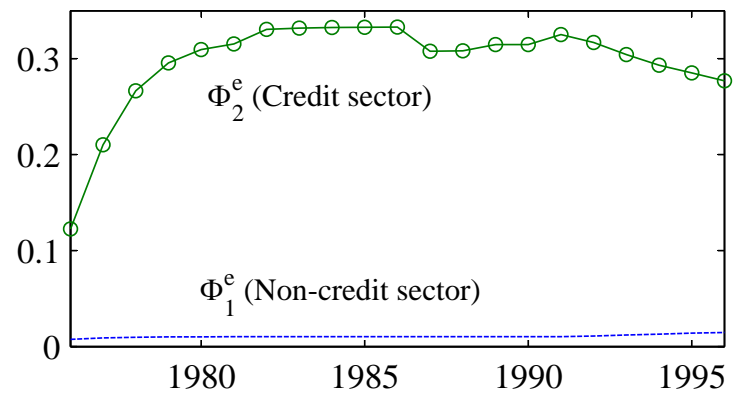

8.6. Profitability Gap

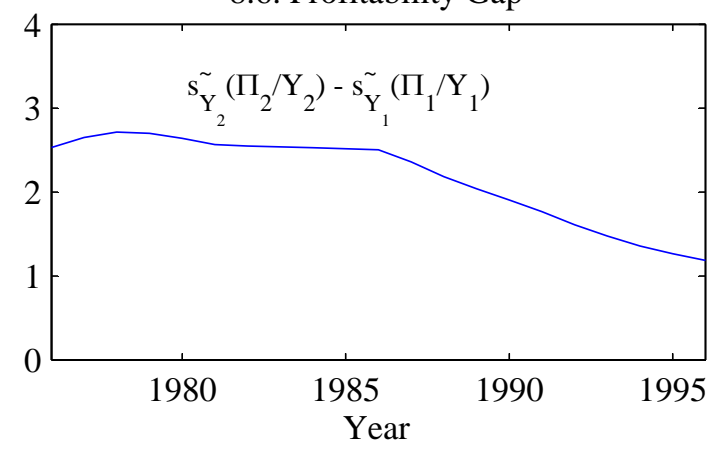

Figure 8. Underlying Variables for Simulated TFP Growth 


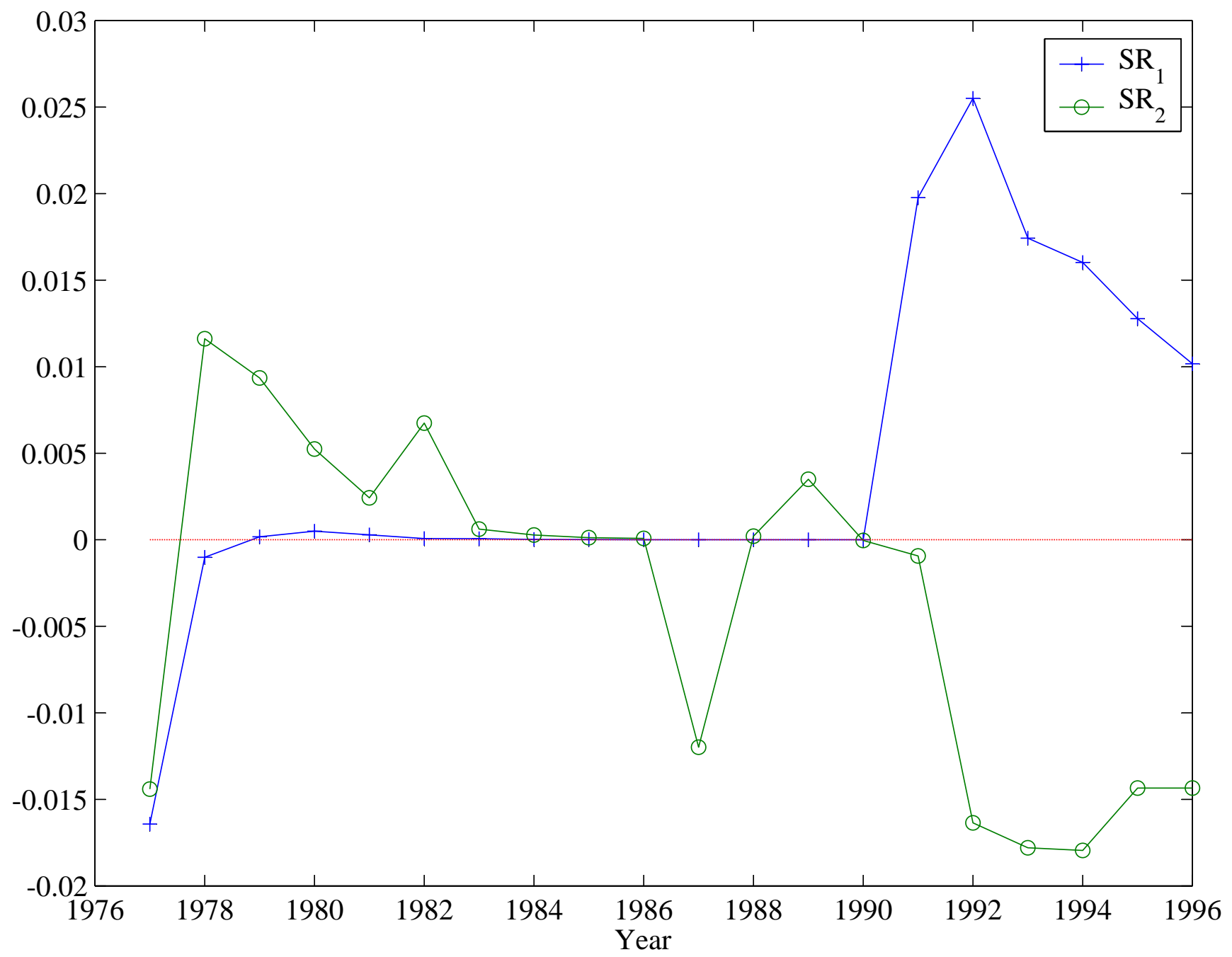

Figure 9. Asymmetric Movements of Sectoral Solow Residuals

Notes: $\mathrm{SR}_{1}=\mathrm{g}_{\mathrm{Y}_{1}}-\left(\mathrm{rK}_{1} / \mathrm{Y}_{1}\right) \mathrm{g}_{\mathrm{K}}$ : Non-credit sector Solow residual. $\mathrm{SR}_{2}=\mathrm{g}_{\mathrm{Y}_{2}}-\left(\mathrm{rK}_{2} / \mathrm{Y}_{2}\right) \mathrm{g}_{\mathrm{K}}:$ Credit sector Solow residual 


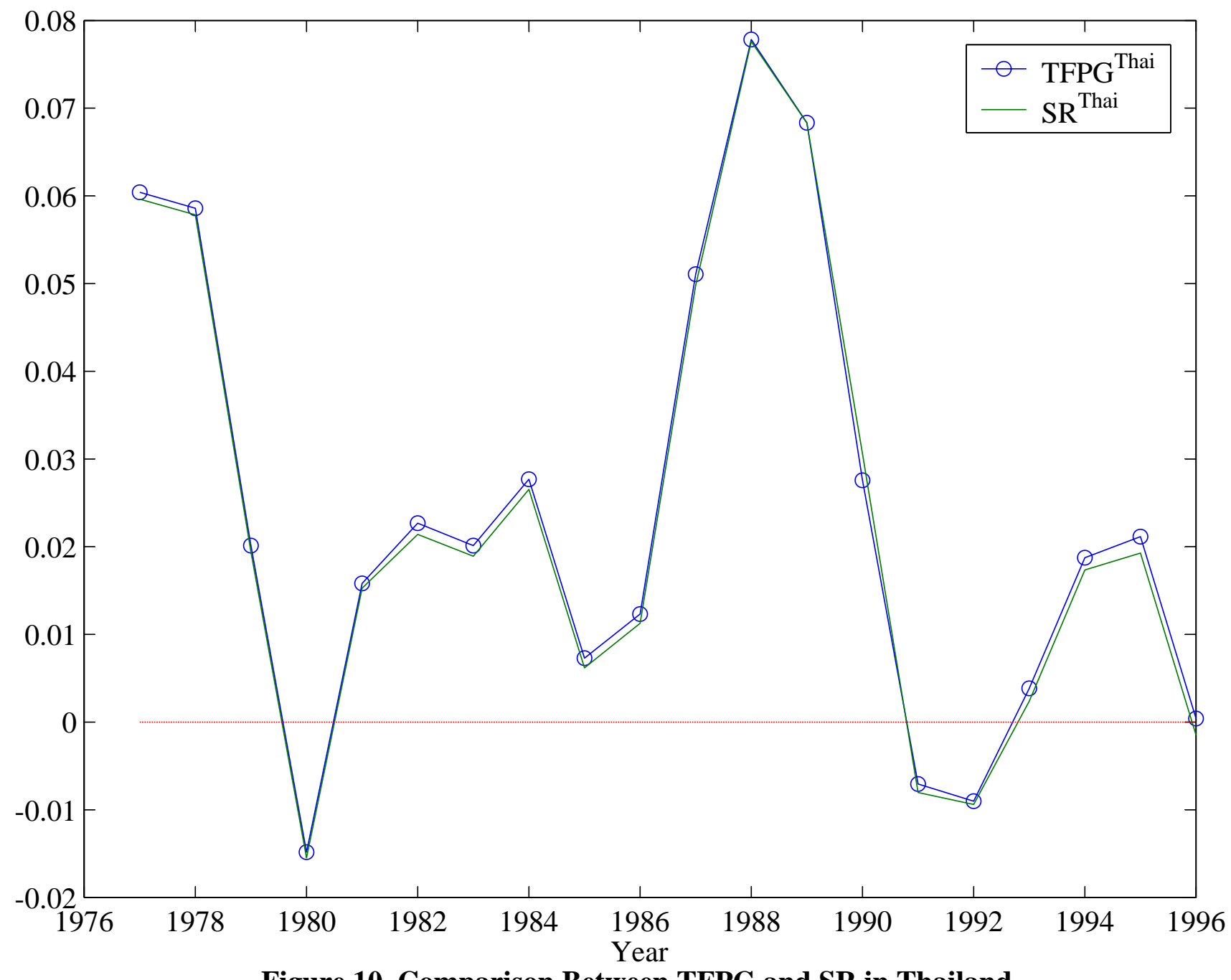

Figure 10. Comparison Between TFPG and SR in Thailand

Notes: TFPG ${ }^{\text {Thai }}$ : TFP growth in equation (46). SR ${ }^{\text {Thai }}$ : Solow residual from standard growth accounting in Figure 1. 


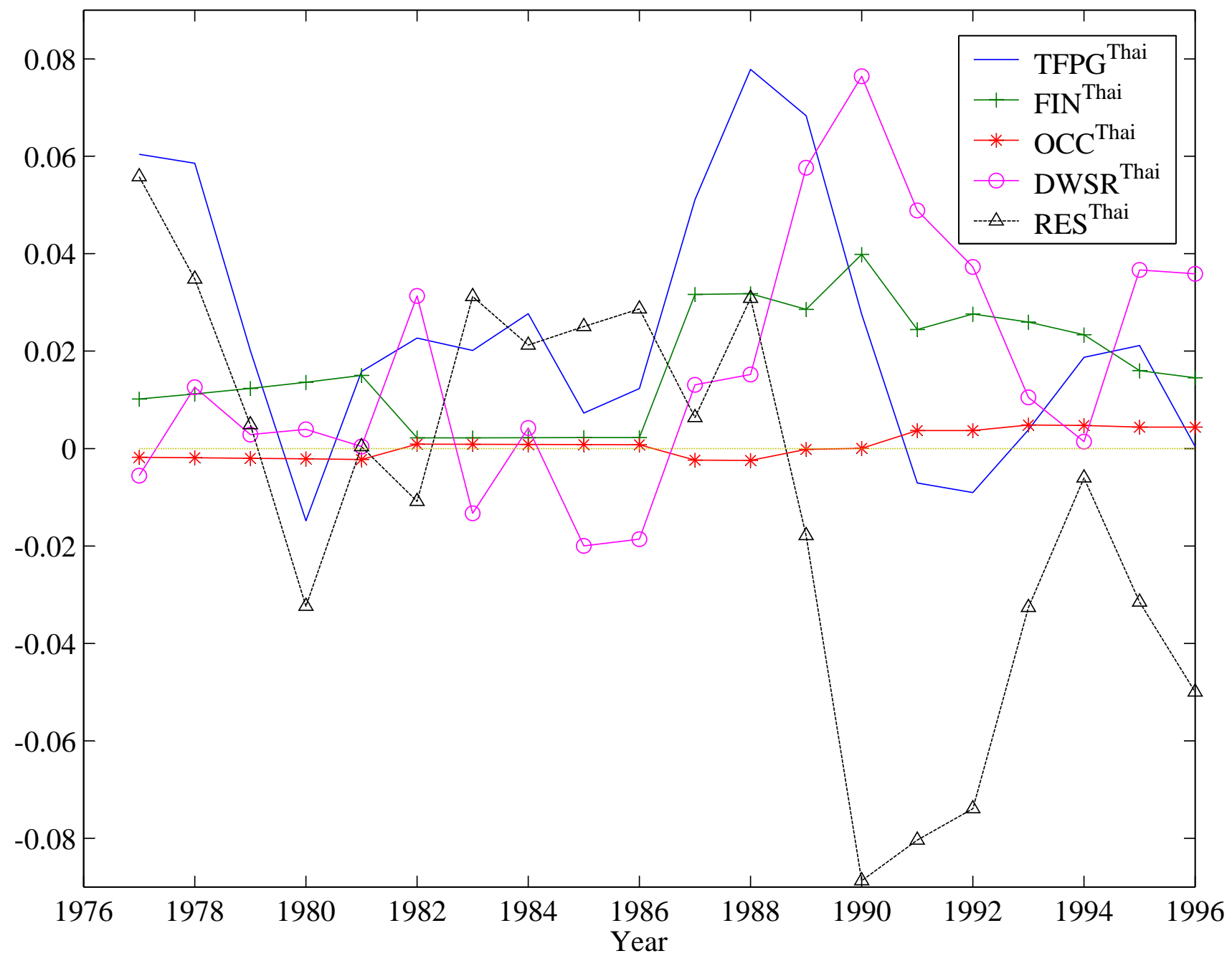

Figure 11. Decomposition of Actual Thai TFP Growth

Notes: TFPG ${ }^{\text {Thai }}$ : TFP growth in equation (46). FIN ${ }^{\text {Thai }}$ : Financial-deepening effect in equation (38). OCC ${ }^{\text {Thai }}$ : Occupational-shift effect in equation (39). DWSR $^{\text {Thai }}$ : Dual within-sector Solow residual in equation (47). RES ${ }^{\text {Thai }}$ : Residual TFP growth in equation (48). 
12.1. Wage (w)
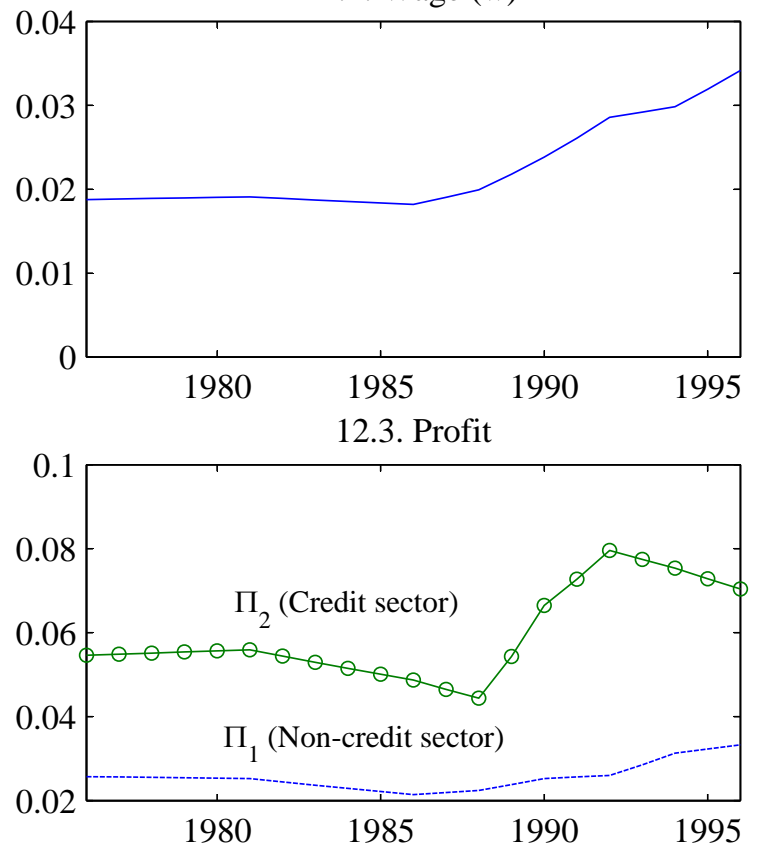

12.5. Sectoral Wage Share

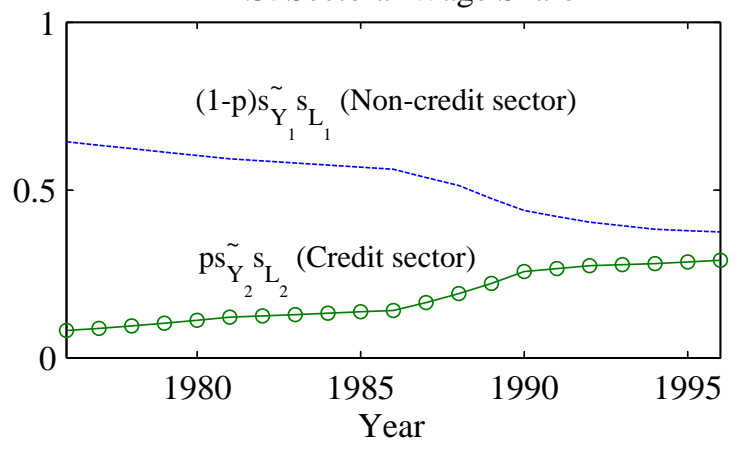

12.2. Interest Rate (r)

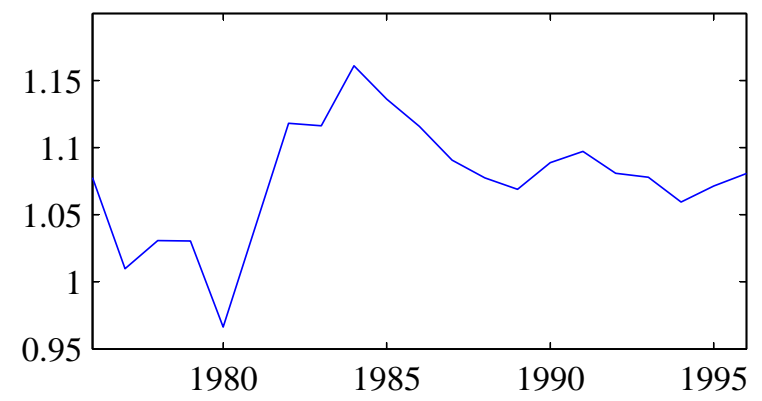

12.4. Sectoral Fraction of Entrepreneurs

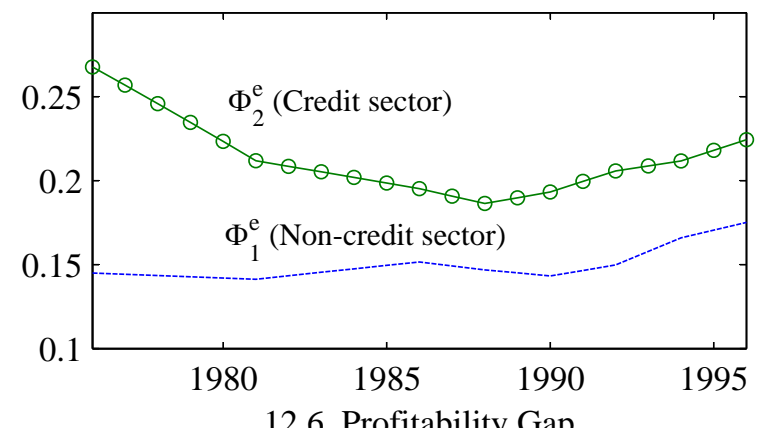

12.6. Profitability Gap

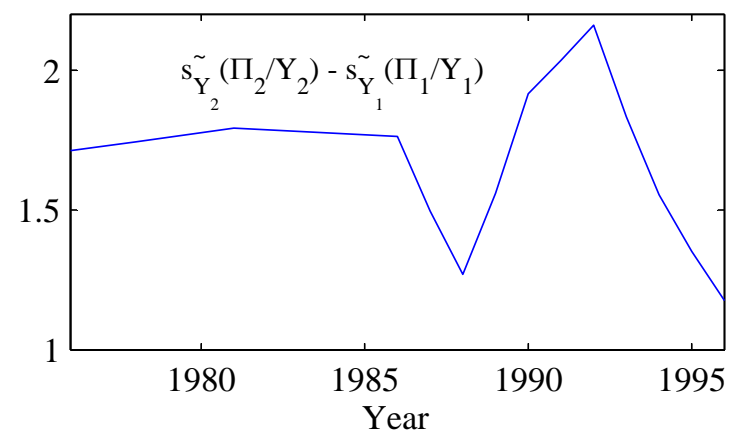

Figure 12. Underlying Variables for Thai TFP Growth 
13.1. Financial-Deepening Effect

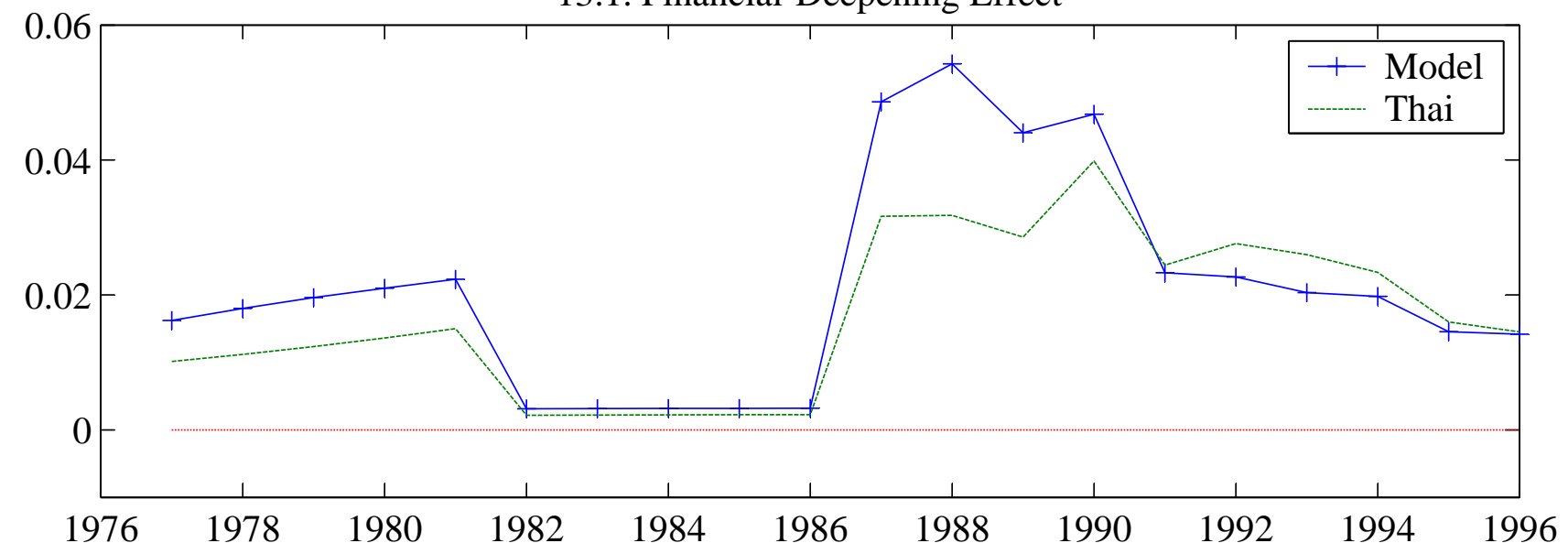

13.2. Occupational-Shift Effect

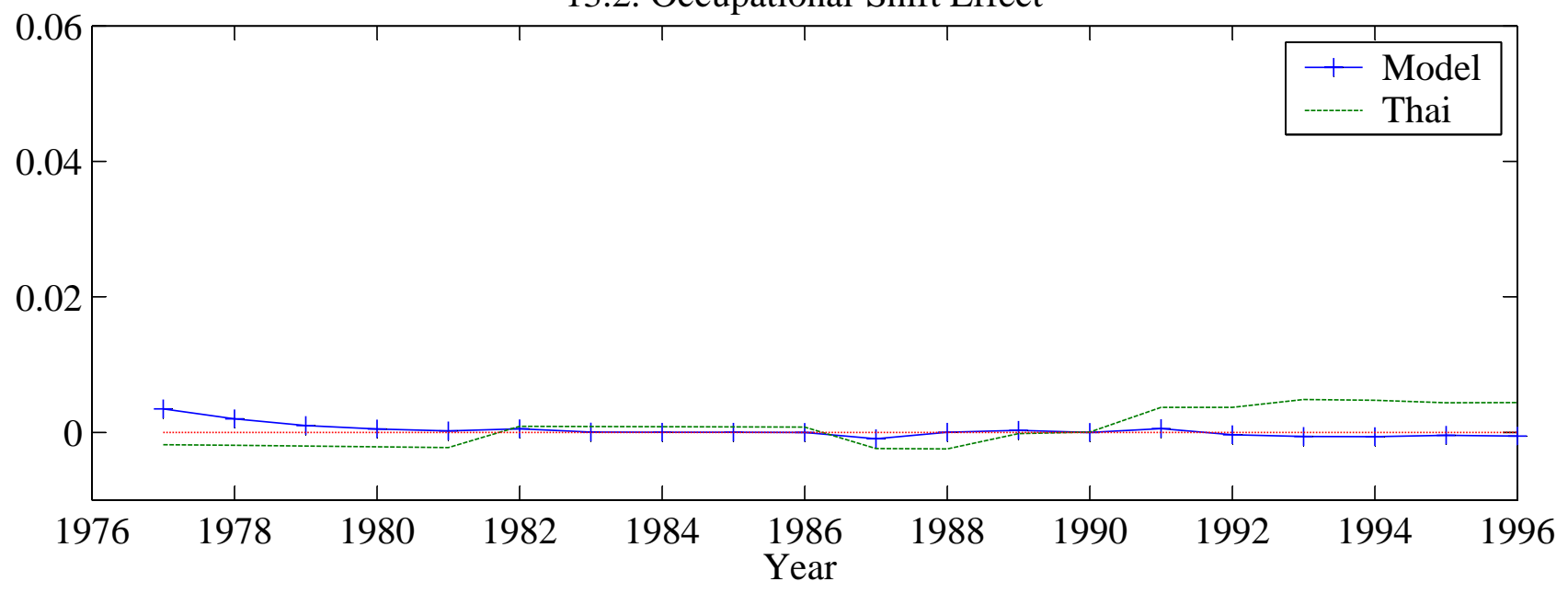

Figure 13. Sources of TFP Growth

Notes: Financial-deepening effect and occupational-shift effect are measured as in equations (38) and (39), respectively. 
14.1. Fraction of Subsisters $\left(\Phi^{\mathrm{S}}\right)$

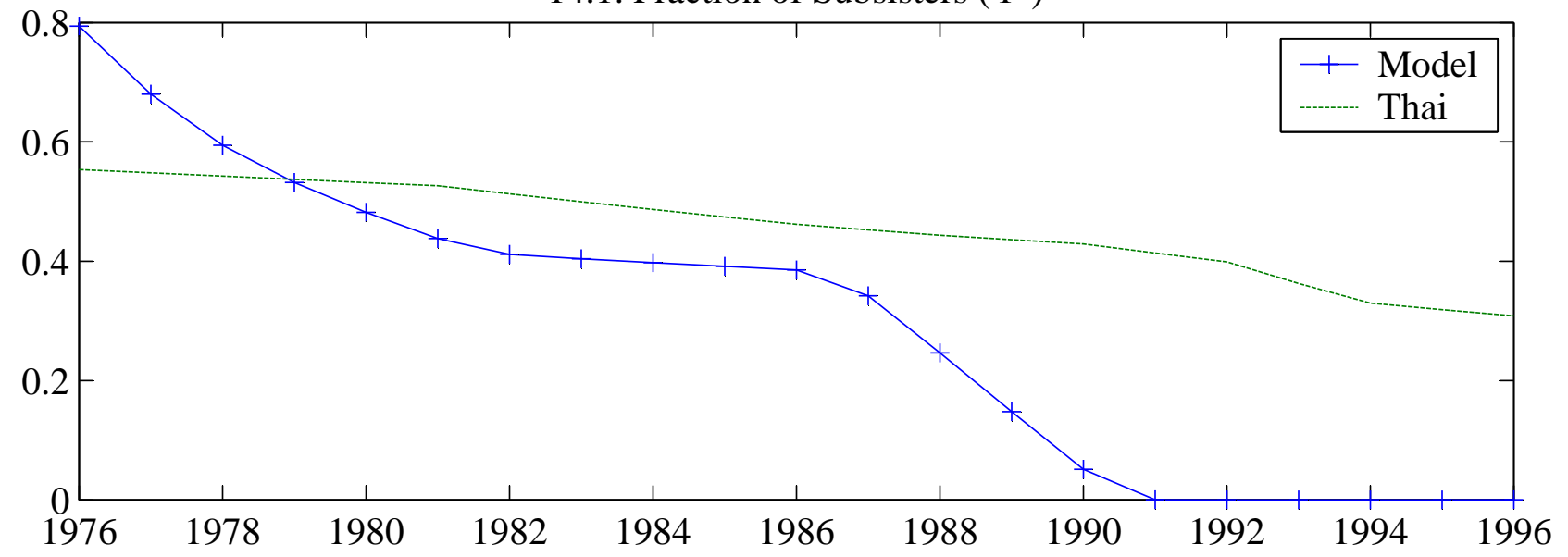

14.2. Fraction of Entrepreneurs in Credit Sector $\left(\Phi_{2}^{\mathrm{e}}\right)$

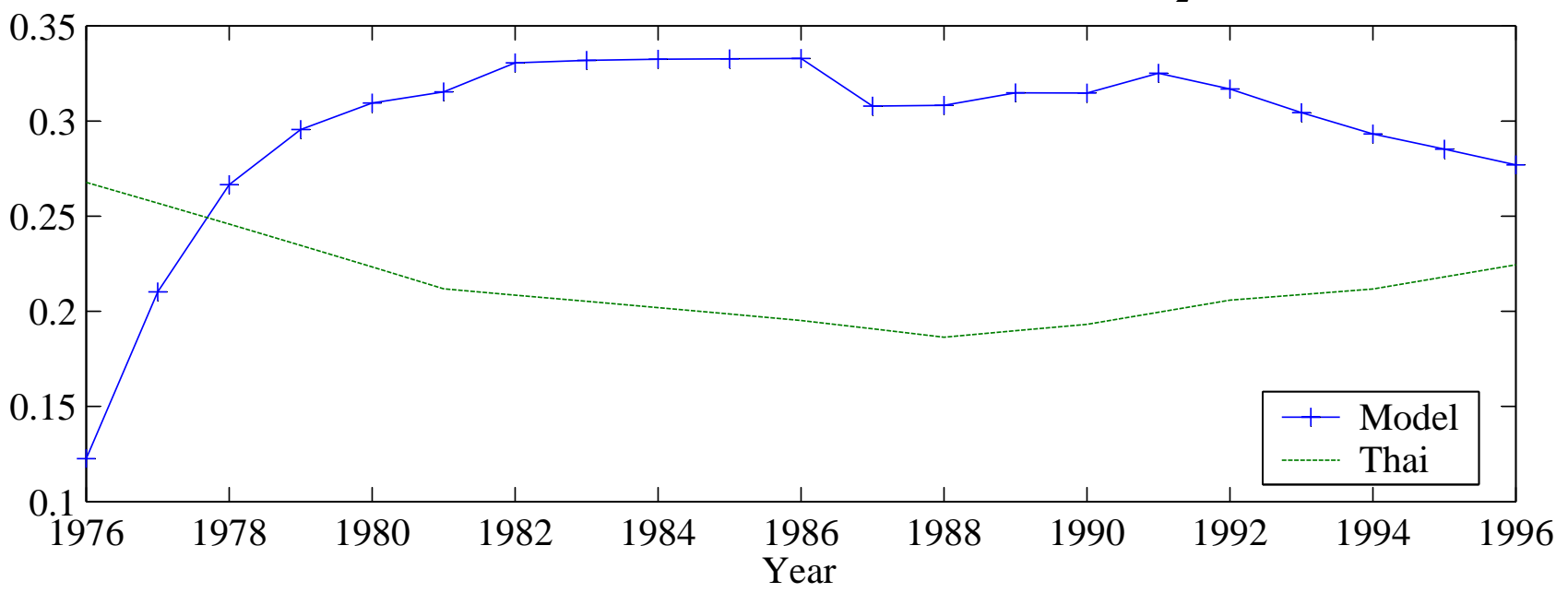

Figure 14. Anomaly 
A1.1. Output Growth

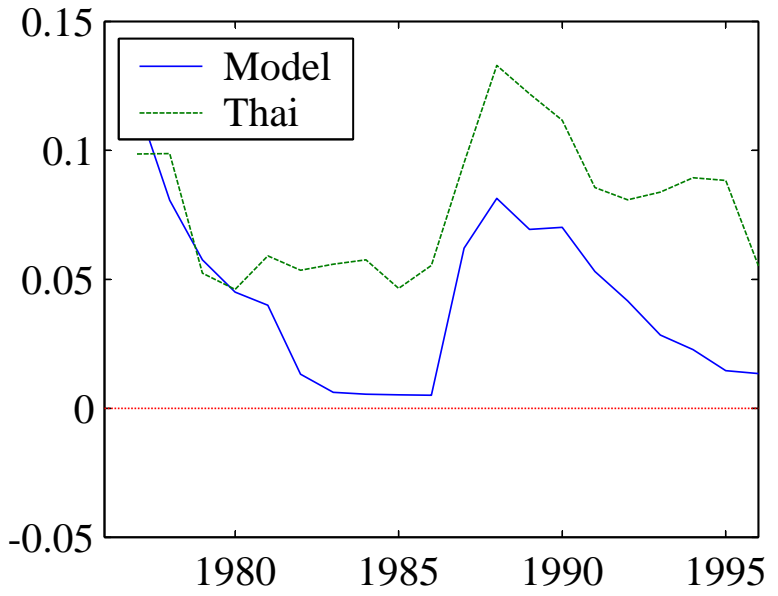

A1.3. Occupational Shift Effect

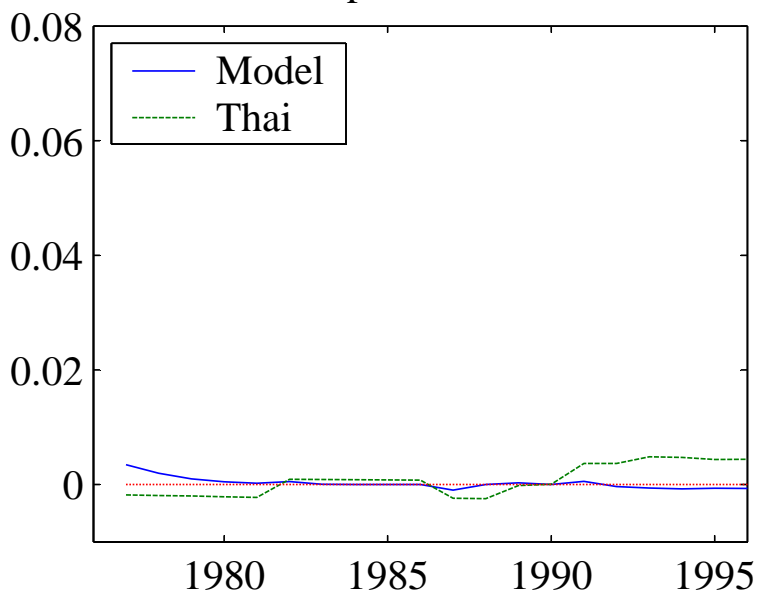

A1.2. TFP Growth

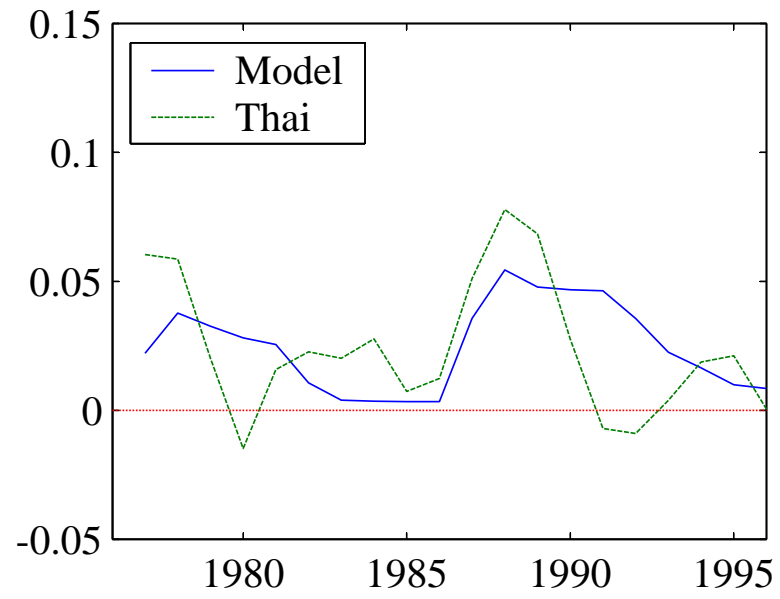

A1.4. Financial Deepening Effect

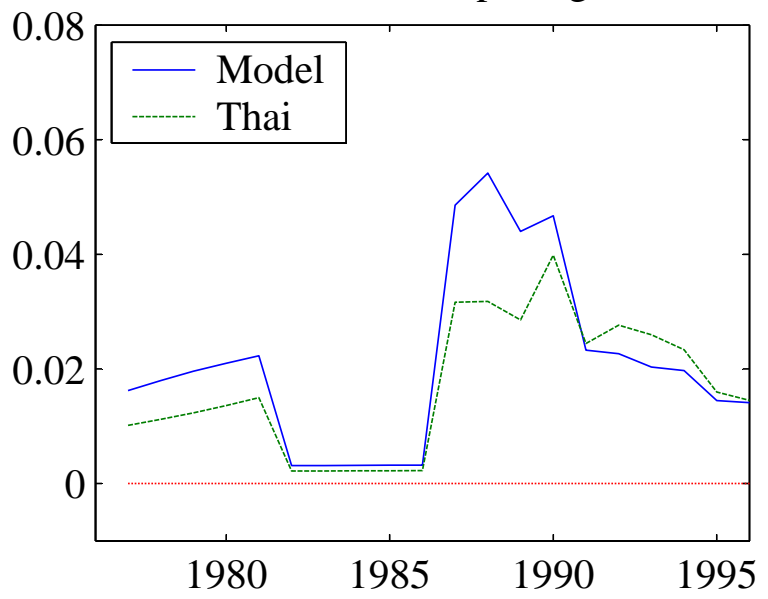

Figure A1. Higher Alpha at $\mathbf{1 . 3 0 0}$ 
A2.1. Output Growth

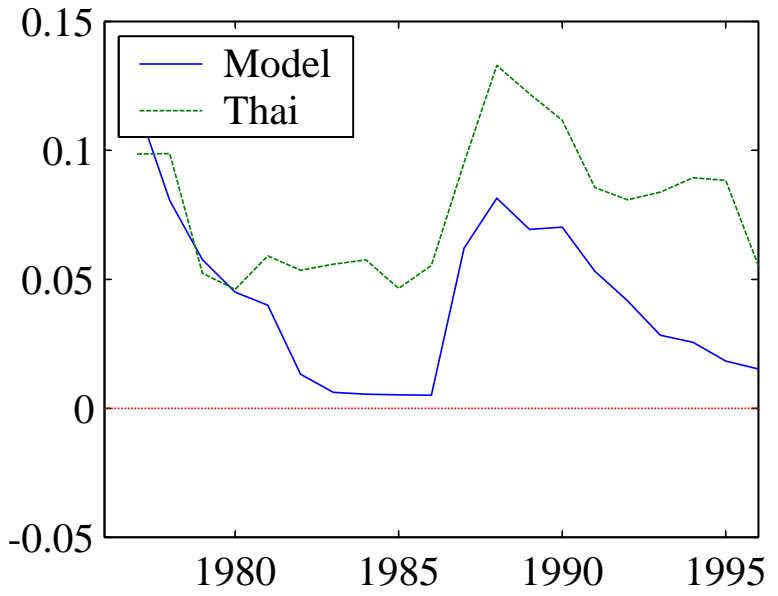

A2.3. Occupational Shift Effect

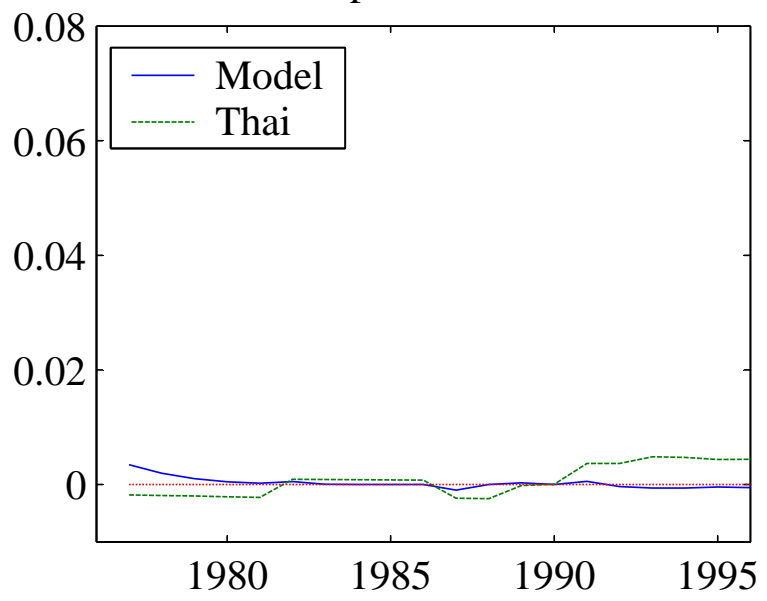

A2.2. TFP Growth

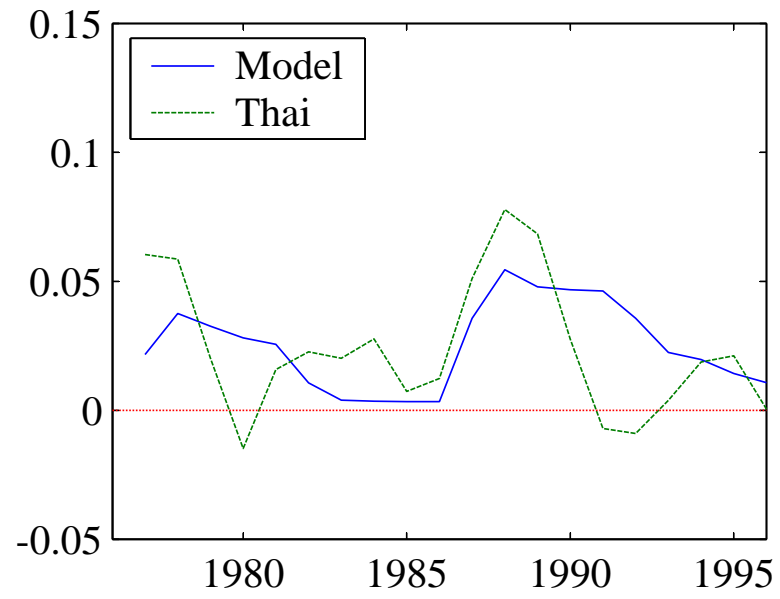

A2.4. Financial Deepening Effect

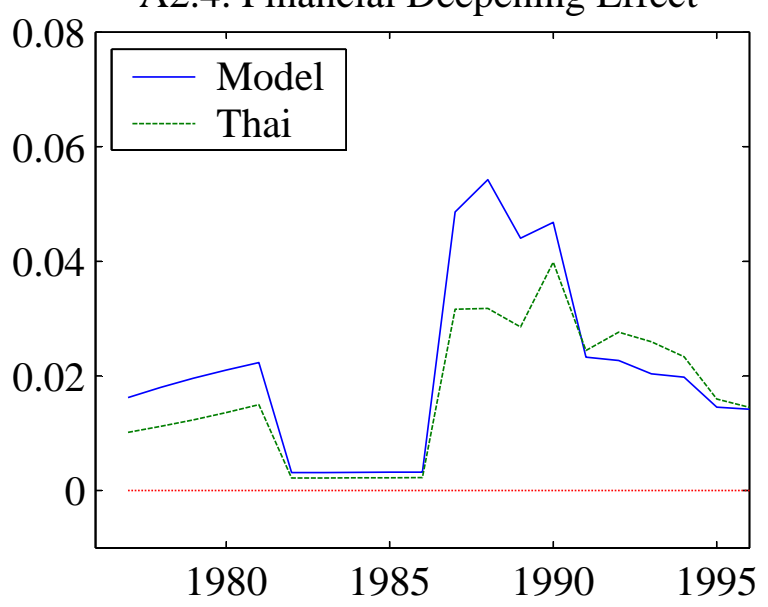

Figure A2. Higher Beta at $\mathbf{0 . 0 1 0 0}$ 
A3.1. Output Growth

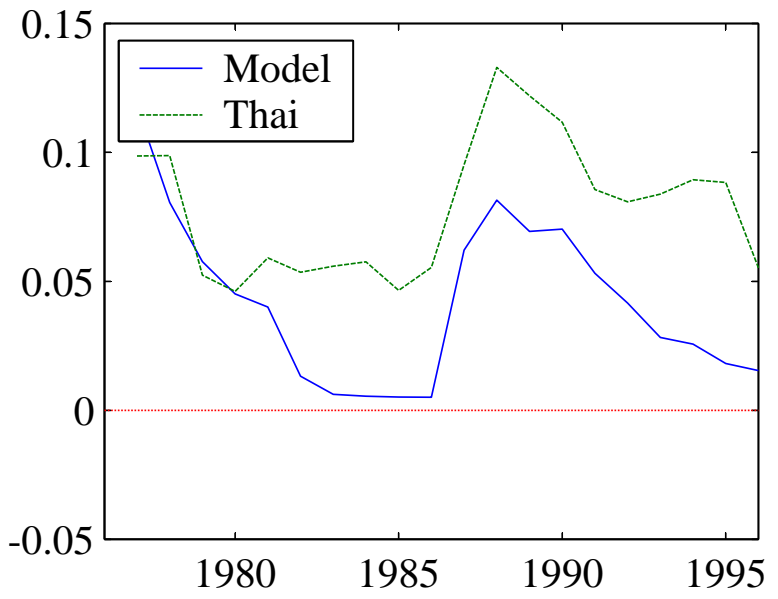

A3.3. Occupational Shift Effect

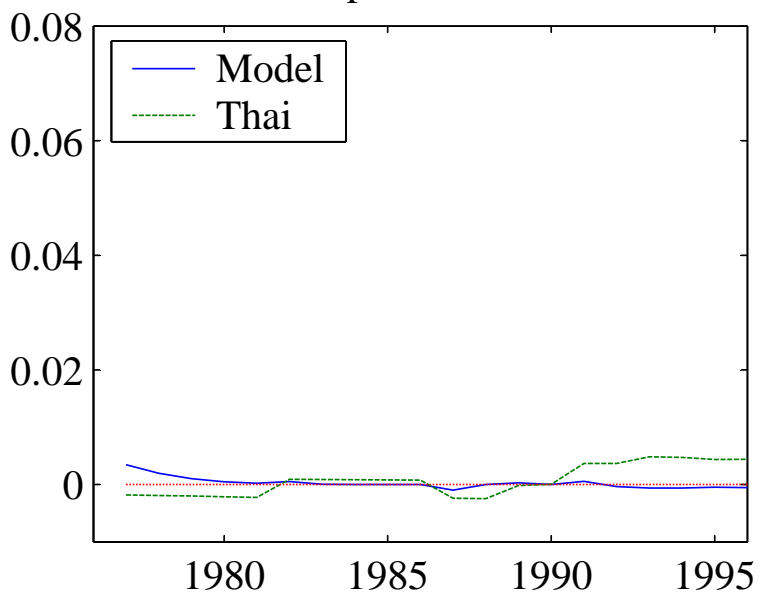

A3.2. TFP Growth

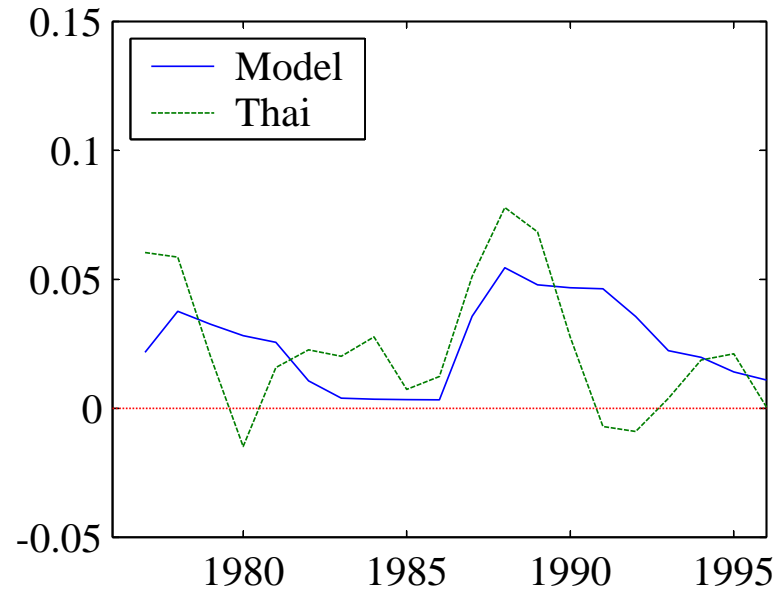

A3.4. Financial Deepening Effect

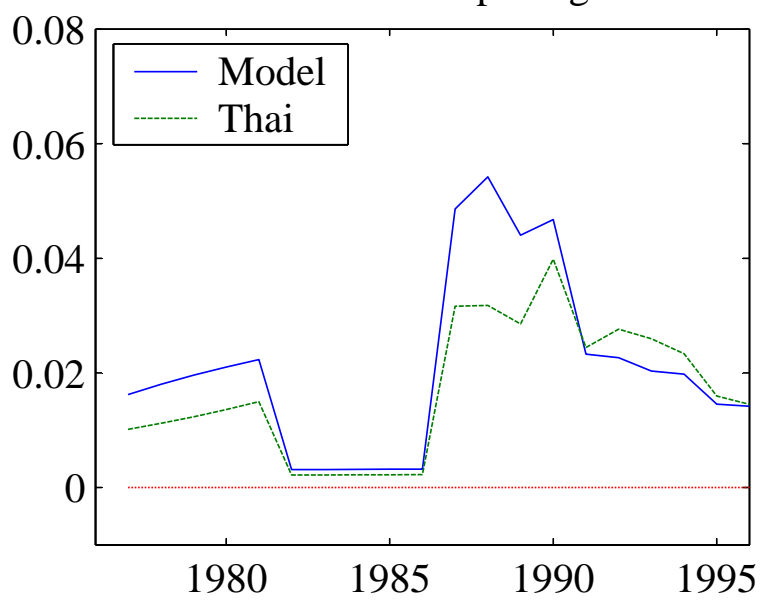

Figure A3. Higher Sigma at 0.0025 
A4.1. Output Growth

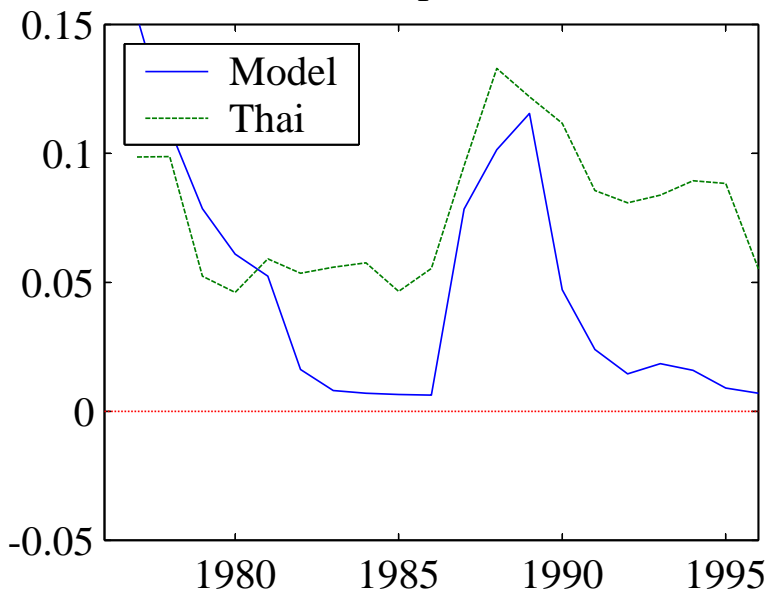

A4.3. Occupational Shift Effect

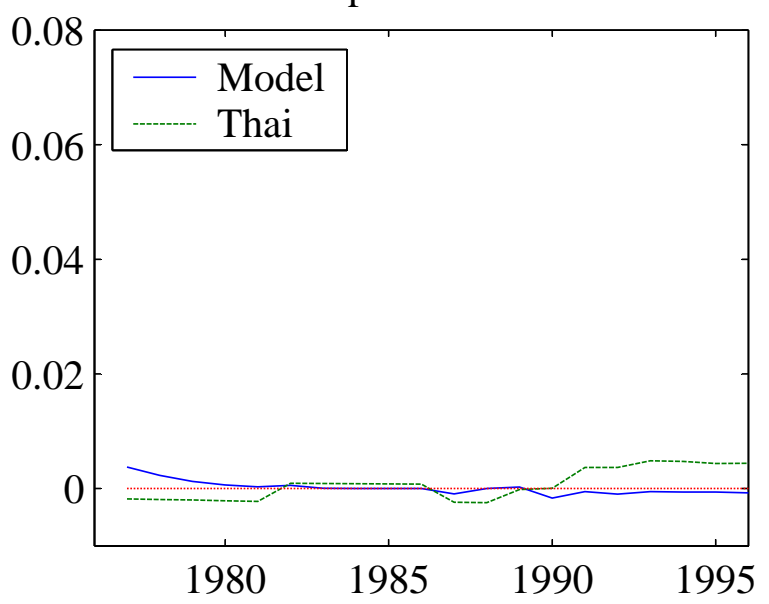

A4.2. TFP Growth

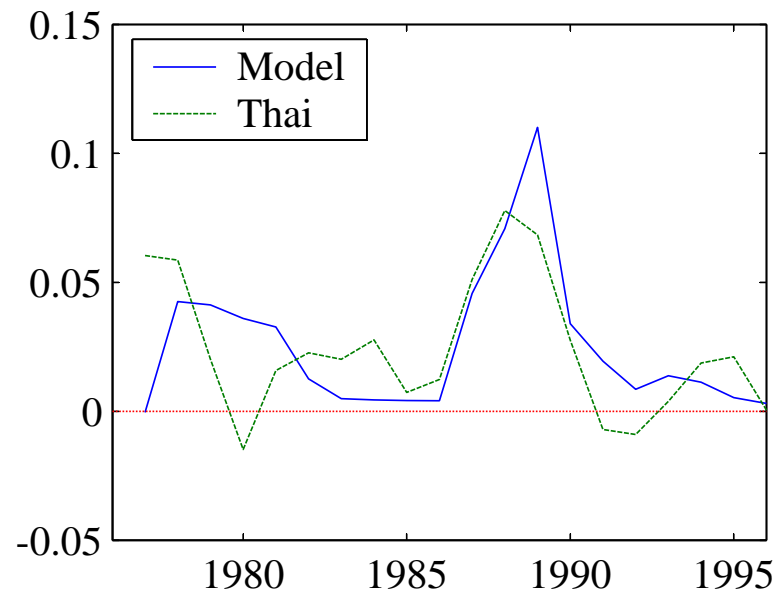

A4.4. Financial Deepening Effect

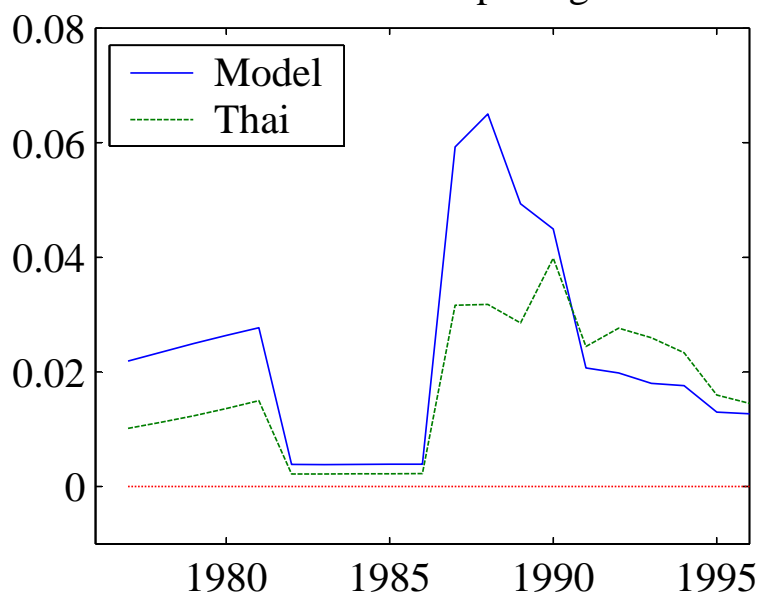

Figure A4. Higher Xi at 0.1100 
A5.1. Output Growth

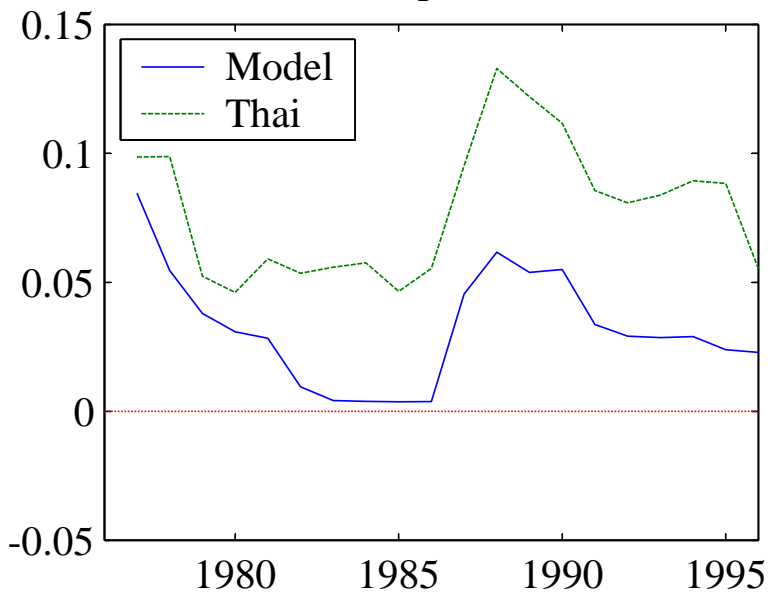

A5.3. Occupational Shift Effect

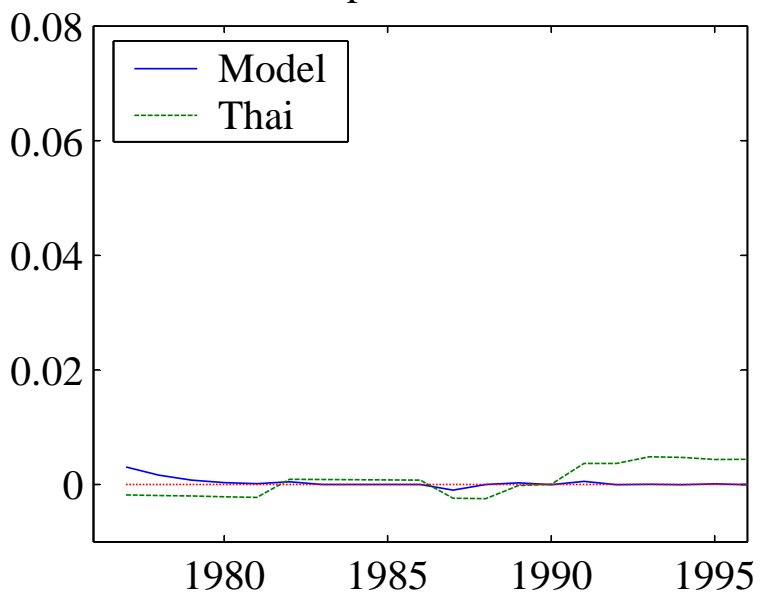

A5.2. TFP Growth

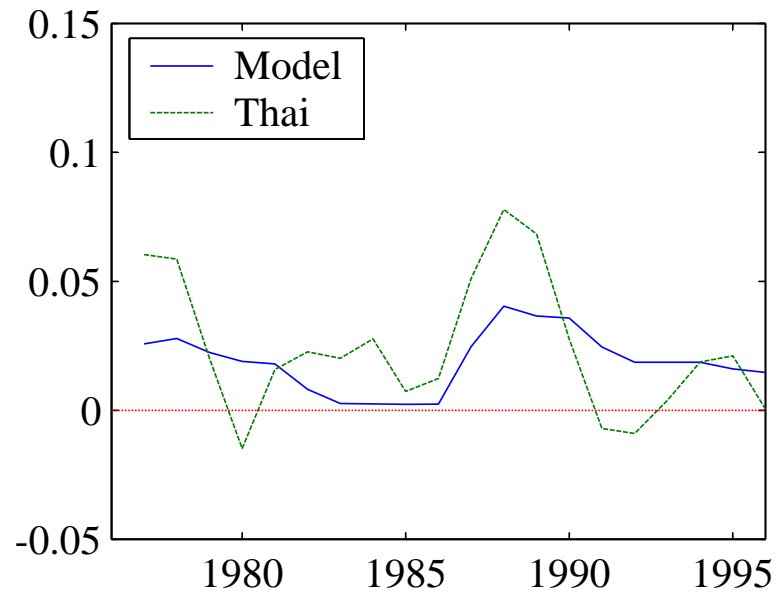

A5.4. Financial Deepening Effect

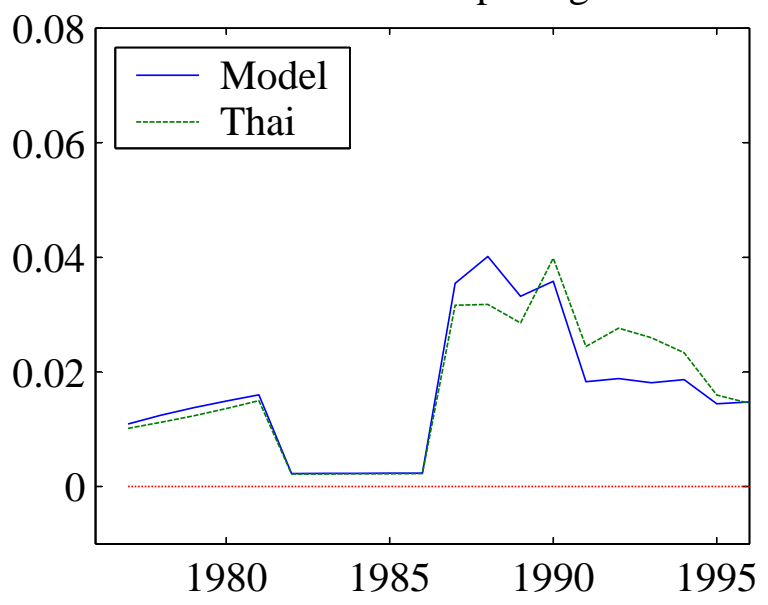

Figure A5. Higher Rho at $\mathbf{0 . 0 0 8 0}$ 
A6.1. Output Growth

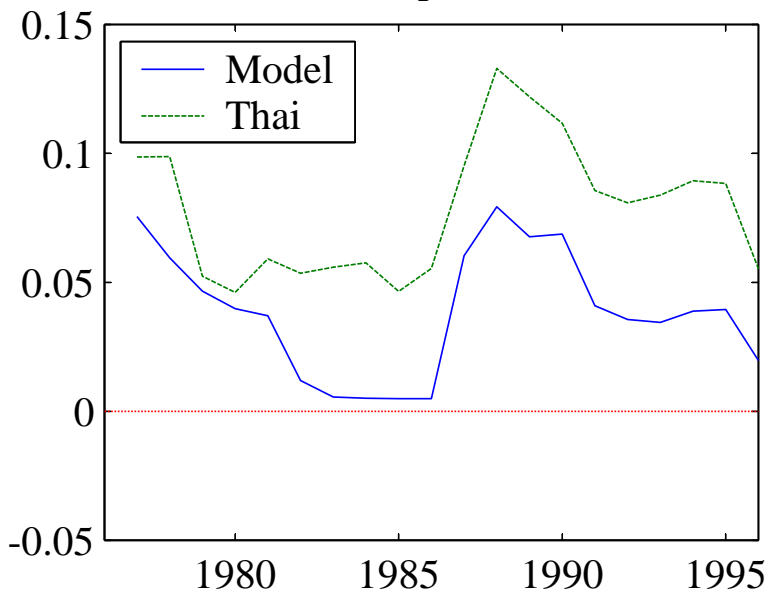

A6.3. Occupational Shift Effect

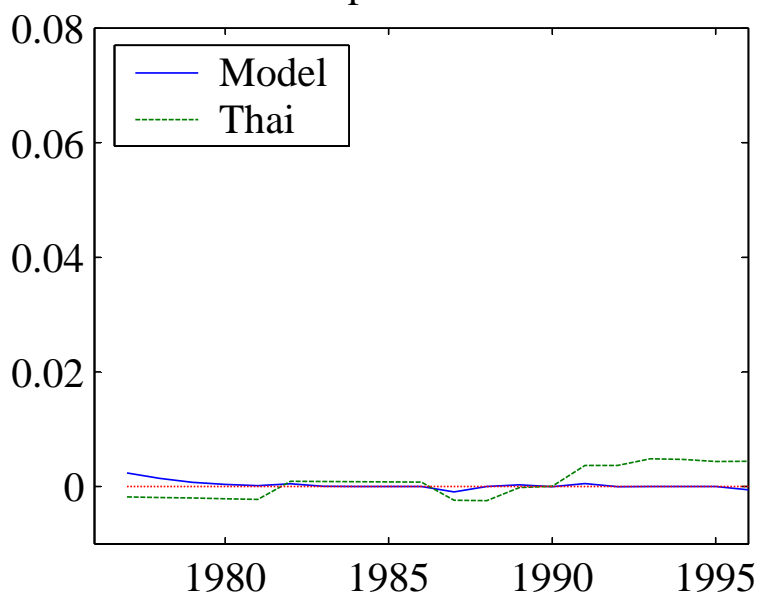

A6.2. TFP Growth

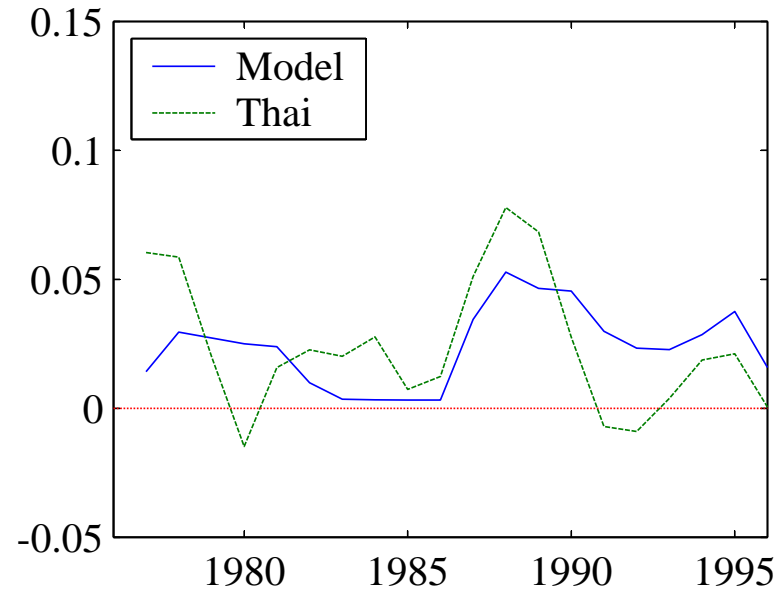

A6.4. Financial Deepening Effect

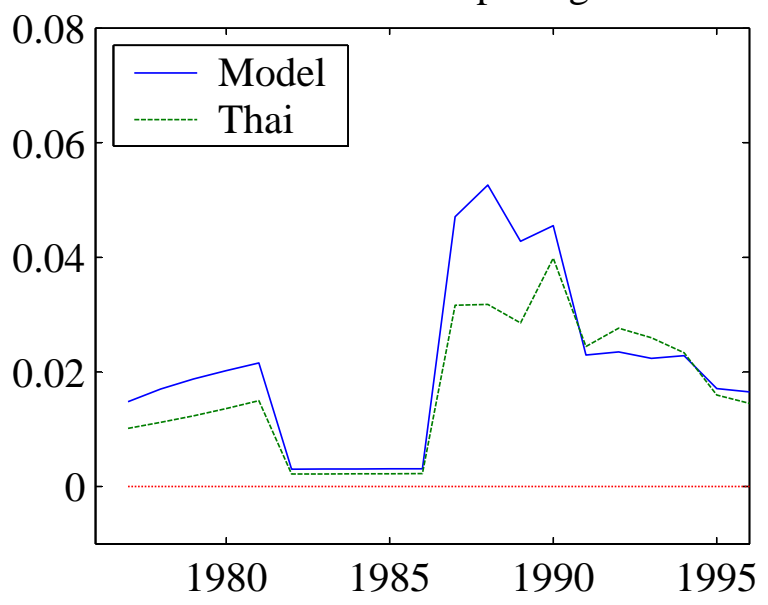

Figure A6. Lower Omega at 0.2500 

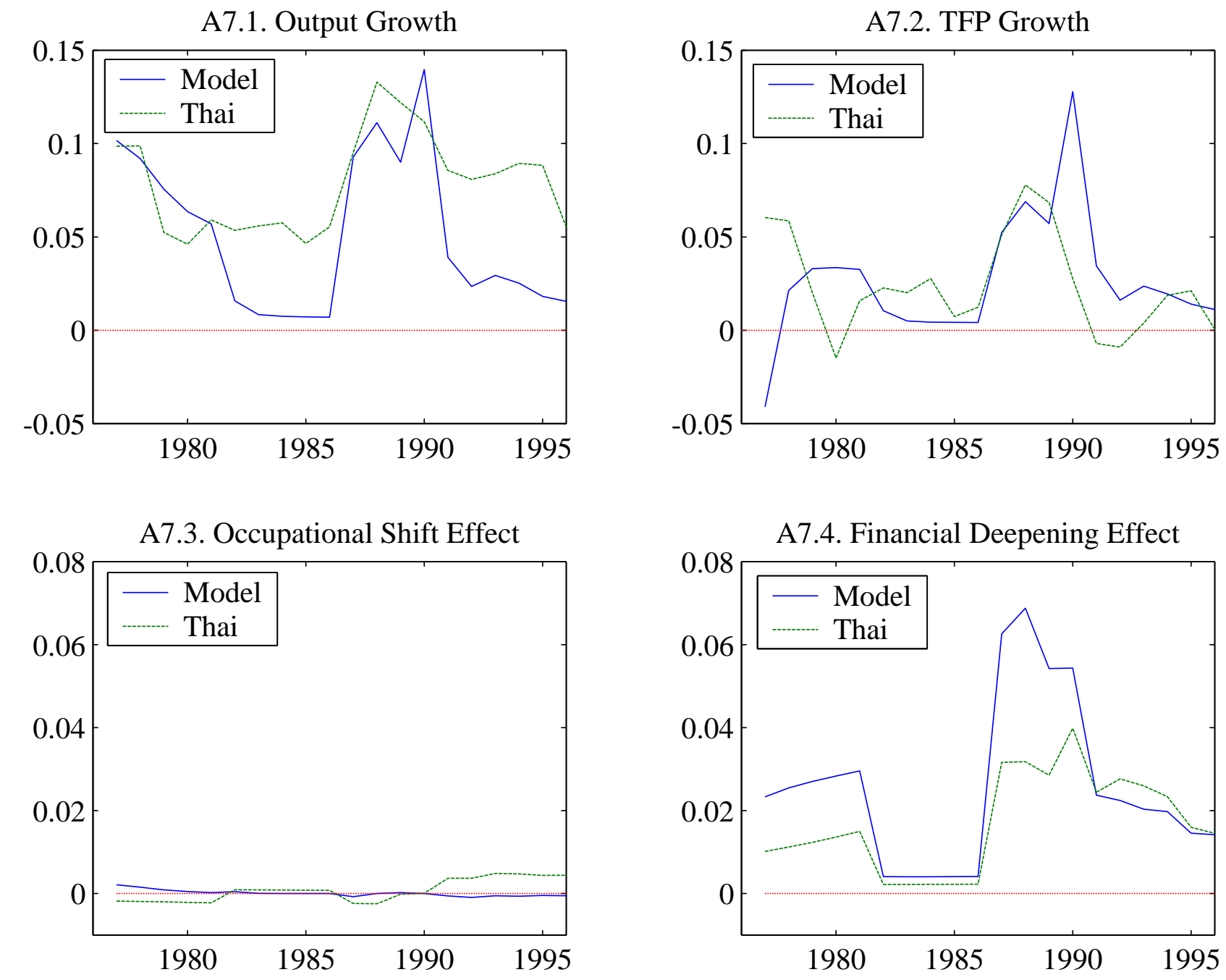

Figure A7. Lower Gamma at 0.0120 